\title{
Data incongruence and the problem of avian louse phylogeny
}

\author{
Vincent S. Smith, Roderic D. M. Page \& Kevin P. Johnson
}

Accepted: 8 July 2003

\begin{abstract}
Smith, V. S., Page, R. D. M. \& Johnson, K. P. (2004). Data incongruence and the problem of avian louse phylogeny. - Zoologica Scripta, 33, 239-259.

Recent studies based on different types of data (i.e. morphological and molecular) have supported conflicting phylogenies for the genera of avian feather lice (Ischnocera: Phthiraptera). We analyse new and published data from morphology and from mitochondrial (12S rRNA and $\mathrm{COI})$ and nuclear $(\mathrm{EF} 1-\alpha)$ genes to explore the sources of this incongruence and explain these conflicts. Character convergence, multiple substitutions at high divergences, and ancient radiation over a short period of time have contributed to the problem of resolving louse phylogeny with the data currently available. We show that apparent incongruence between the molecular datasets is largely attributable to rate variation and nonstationarity of base composition. In contrast, highly significant character incongruence leads to topological incongruence between the molecular and morphological data. We consider ways in which biases in the sequence data could be misleading, using several maximum likelihood models and LogDet corrections. The hierarchical structure of the data is explored using likelihood mapping and SplitsTree methods. Ultimately, we concede there is strong discordance between the molecular and morphological data and apply the conditional combination approach in this case. We conclude that higher level phylogenetic relationships within avian Ischnocera remain extremely problematic. However, consensus between datasets is beginning to converge on a stable phylogeny for avian lice, at and below the familial rank.

Vincent S. Smith \& Roderic D. M. Page, Division of Environmental and Evolutionary Biology, University of Glasgow, Graham Kerr Building, Glasgow G12 8QQ, UK. E-mail:v.smith@bio.gla.ac.uk, r.page@bio.gla.ac.uk

Kevin. P. Johnson. Illinois Natural History Survey, 607 East Peabody Drive, Champaign, Illinois 61820-6970, USA. E-mail: kjobnson@inbs.uiuc.edu
\end{abstract}

\section{Introduction}

Lice (Phthiraptera) comprise some 4900 valid species. These insects are permanent obligate ectoparasites present on a diverse selection of birds and mammals with a worldwide distribution. Historically, lice have played a prominent role in our understanding of the patterns and processes of evolution, and lice continue to play a key role into research on the evolution of host-parasite associations. Having dominated recent methodological and empirical debates on cospeciation (Page 2002), lice are model organisms for investigating the host correlates of parasite diversification (Clayton et al. 1999), parasite specialization (Smith 2001), and modes of speciation (Clay 1949; Rózsa 1993). Recent work has also begun to place lice at the forefront of parasite comparative ecological research, permitting studies to determine the ecological basis of the host-louse coevolutionary history (Clayton et al. 2002), parasite mediated sexual selection (Loye \& Zuk 1991), and the determinants of parasite community structure (Choe \& Kim 1988; Rózsa et al. 1996).

Despite this interest in Phthiraptera, a comprehensive analysis leading to a widely accepted phylogeny of higher- level relationships has proved elusive. In this regard, one suborder of lice, the Ischnocera, has proven particularly problematic. Ischnocera comprise almost two-thirds of all described louse species, and have been the focus of most phylogenetic studies on lice to date. These have tended to concentrate on groups of lice that are clearly circumscribed by their host association, examining well-sampled clades at the tips of the louse tree, to address questions on cospeciation and comparative rates of evolution (Hafner \& Nadler 1990; Smith 2000; Johnson et al. 2001a,b, 2002). More recently, attempts have been made to take a broader phylogenetic perspective to delimit the major ischnoceran louse lineages and resolve their interrelationships (Cruickshank et al. 2001; Smith 2001; Johnson \& Whiting 2002; Barker et al. in press). These studies have the potential to address important macroevolutionary questions about the early evolution of hosts and their lice, such as the role of cospeciation in shaping early louse diversification, the rate of this diversification, and the relative antiquity of the major louse clades and their hosts. Robust phylogenies are a prerequisite for these types of analyses. However, as yet, much of the data has proven 
insufficient to address these issues, and whilst studies of these relationships are still in their relative infancy, consensus over the boundaries of the major families and their relationships is at an impasse.

The goal of this study is to examine the discordance between the available molecular and morphological data, supplemented by new data for a set of key ischnoceran taxa. We put particular emphasis on the issue of data quality to address the extent and causes of disparity between each dataset, and summarize a set of core relationships extracted from the available data. Finally, within this framework we use simulation methods to explore the value of sequencing additional data for the genes predominantly used in louse phylogenetic work, highlighting the necessity of exploring other genes to address basal louse relationships beyond those that have been used to date.

\section{Current bypotheses and classifications}

The classification of Ischnocera is extremely contentious, with the number of proposed families ranging from two (Hopkins \& Clay 1952) to 21 (Eichler 1963). Little justification has been produced for any of these schemes, and assessment of their host-parasite implications is difficult, amid accusations that their authors were unduly biased by knowledge of the louse-host associations when these classifications were derived (Johnson \& Clayton 2003).

Smith (2001) was the first to take a strictly phylogenetic approach to addressing basal ischnoceran relationships. Focusing on the avian Ischnocera, this morphological phylogeny included representatives from approximately one third of all genera. Subsequently, Cruickshank et al. (2001) and Barker et al. (in press) have taken a molecular approach with the nuclear genes EF1- $\alpha$ and $18 \mathrm{~S}$ rRNA, respectively. However, a cursory inspection of these trees reveals striking incongruence, particularly at the deeper level between the molecular and morphological studies. This can be examined with reference to the two major character types described in Fig. 1. These characters define gross aspects of louse anatomy, and relate to the principal ecological niches occupied by lice on their hosts. When mapped on to Smith's morphological phylogeny they suggest a conserved pattern of evolution in which characters based on ontogenetic transformations of the head define the two principal ischnoceran clades - the so called circumfasciate and noncircumfasciate lice. More terminal clades have convergently evolved to exploit different ecological niches on the host (Fig. 2A). This explanation was used by Smith (2001) to explain why multiple clades of lice are often present on the same host species. It also suggests that sympatric speciation played a limited role in shaping the evolution of most louse assemblages, since lice present on the same host were never sister taxa. The molecular hypotheses are harder to interpret.
A. Circumfasciate Head
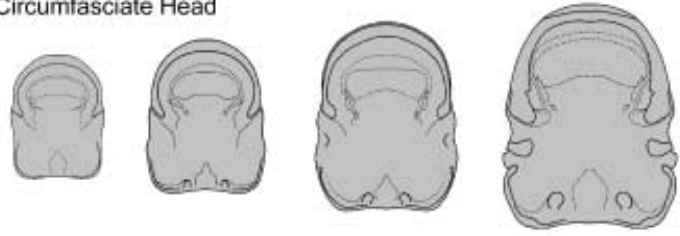

B. Non-Circumfasciate Head
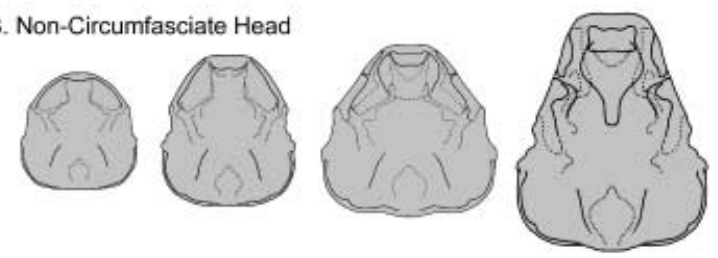

N I

N II

$\mathrm{N}$ III

Adult
C. Wing Lice

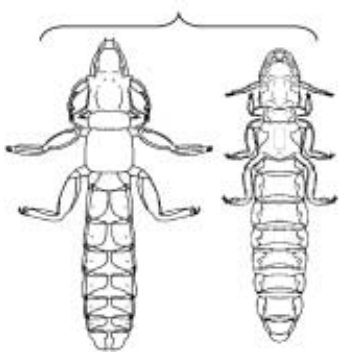

D. Body Lice

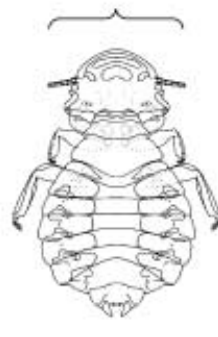

E. Head Lice

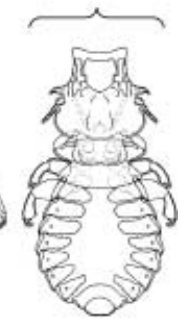

Fig. 1 A-E. Principal characters defining major clades of avian ischnoceran lice. - A. Circumfasciate. - B. Noncircumfasciate head types showing typical ontogenetic transformations through each louse instar. These affect the plasticity of the head capsule and ultimately the method of attachment to the host. - C. Wing lice. - D. Body lice. -E. Head lice. These correspond to the principal niches occupied by the lice on the host's body.

In part this is due to a lack of consensus between the principal molecular datasets. However, the strongly supported clades defined by head morphology are not present in any of the molecular hypotheses, and the ontogenetic head characters defined by Smith (2001) are interpreted to have convergently evolved on numerous occasions throughout the tree (Fig. 2B). Based on molecular data, the traditional groupings of circumfasciate and noncircumfasciate lice are not recognized, and a more complicated macroevolutionary pattern emerges.

\section{Dataset incongruence}

The lack of consensus for ischnoceran louse taxonomy has implications for choice of taxa in cophylogenetic analyses. Robust sampling of parasite clades is a prerequisite for studies of host-parasite cospeciation (Clay 1949; Page et al. 1996); however, this is difficult when the clades are ill defined by current taxonomy. Taxa are currently chosen on the basis of 

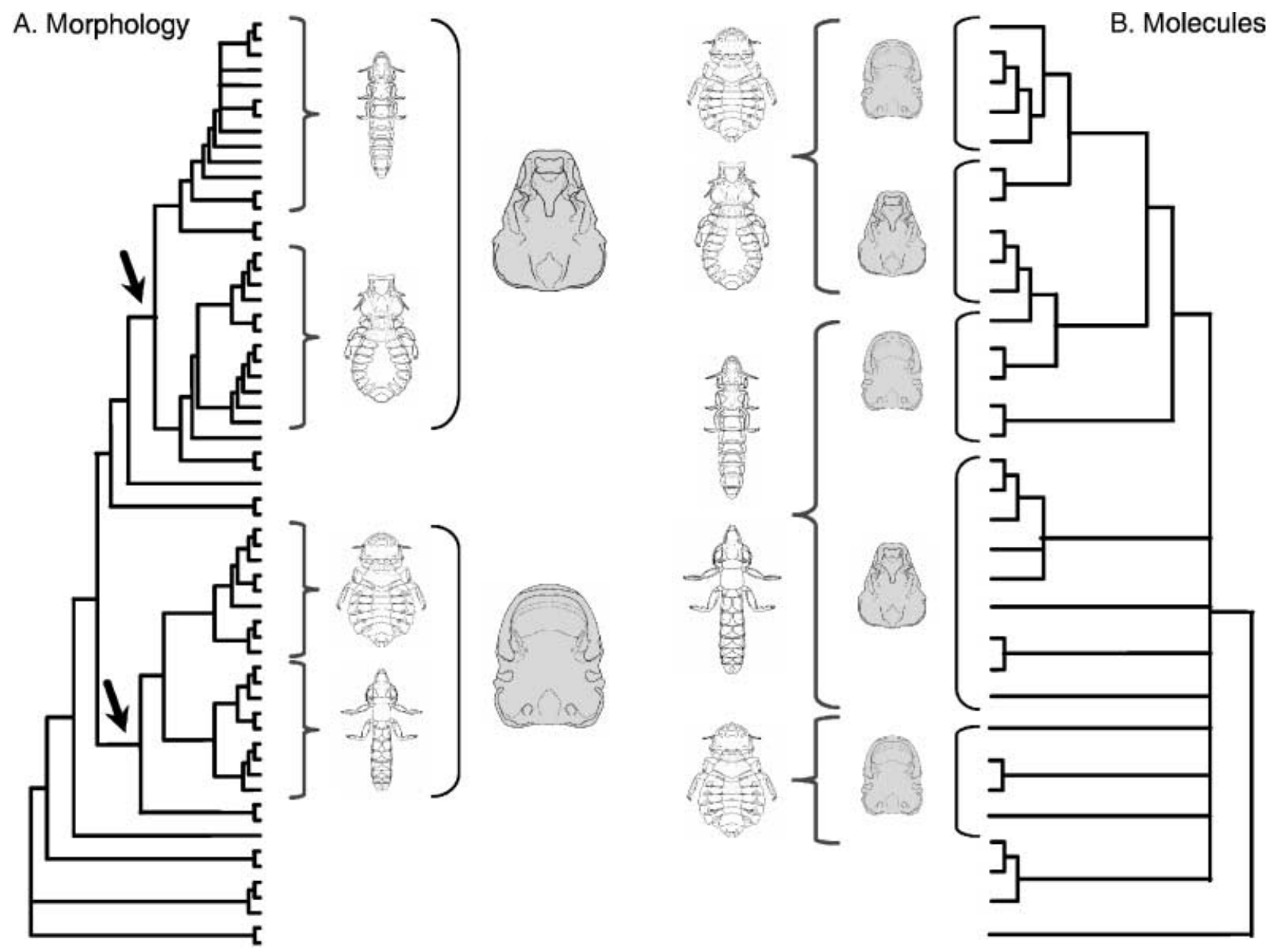

Fig. 2 Current estimates of avian louse phylogeny, highlighting the conflict between the molecular and morphological hypotheses. Key nodes recovered by morphology but not the molecular data are highlighted by arrows.

host association, potentially biasing studies of cophylogeny and leading to inaccurate estimates of cospeciation. The macroevolutionary forces that shape louse evolution are also difficult to resolve when current estimates of louse phylogeny differ dramatically. One might argue that convergence in anatomical characters of the head has biased the morphological estimate of louse phylogeny. Alternatively, problems with the molecular estimate, such as the high ratio of taxa to characters in the study by Cruickshank et al. (2001) limit the resolution of the molecular data.

We include in our analyses additional sequences from two mitochondrial genes, domain III of $12 \mathrm{~S}$ rRNA (new data reported here) and COI (predominantly new data, see Table 1). We have also sequenced additional taxa to supplement the nuclear dataset for Elongation Factor 1 alpha (Cruickshank et al. 2001). Limited taxon coverage for the $18 \mathrm{~S}$ rRNA gene precludes a 'total evidence' combined analysis (sensu Kluge 1989). However, results from this nuclear gene were compared with results from the mitochondrial, nuclear and morphological data presented here.

One problem with previous studies comparing different datasets is that exemplar species taken from the possible clades within Ischnocera have differed widely between studies. We chose a set of exemplars that maximizes the overlap among the molecular studies and the morphological investigation of Smith (2001). These consolidate the largest number of new and previously used ischnoceran characters to date. To compare the DNA and morphological data, we constructed a new data matrix of all available morphological and molecular characters for these taxa. The solution to the problem of incongruence should inform not only the deeper pattern of host-louse coevolutionary history and radiation, but also the underlying causes of incongruence among data from different sources. 
Avian louse phylogeny $•$ V.S. Smith et al.

Table 1 Specimens, hosts, and sequences included in the molecular component of this study. Missing GenBank numbers are indicated with a dash. Specimens examined for morphological characters are listed in Appendix I of Smith (2001).

\begin{tabular}{|c|c|c|c|c|}
\hline \multirow[b]{2}{*}{ Species } & \multirow[b]{2}{*}{ Host } & \multicolumn{3}{|c|}{ GenBank Accession nos. } \\
\hline & & EF1- $\alpha$ & $12 S$ rRNA & $\mathrm{COI}$ \\
\hline Acidoproctus emersoni & Dendrocygna eytoni & - & AY314846 & AY314806 \\
\hline Alcedoecus alatoclypeatus & Halcyon malimbica & AY314825 & AY314847 & AY314807 \\
\hline Anaticola crassicornis & $\begin{array}{l}\text { Anas (superciliosa) superciliosa, } \\
\text { A. undulata, } A \text {. (platyrhynchos) platyrhynchos }\end{array}$ & AF320353 & AF396482 & AY314805 \\
\hline Aquanirmus sp. & Poliocephalus poliocephalus & AY314826 & AY314848 & AY314808 \\
\hline Archolipeurus nandu & Rhea americana & AF320360 & AY314849 & AF545768 \\
\hline Ardeicola geronticorum & Geronticus calvus & - & AF396486 & AF396545 \\
\hline Ardeicola sp. & Ardea cinerea & AF320361 & - & - \\
\hline Austrogoniodes waterstoni & Eudyptula minor & AF320362 & AF189129 & AF348859 \\
\hline Bovicola bovis & Bos taurus & AF320370 & - & AF545680 \\
\hline Brueelia sp. & Merops gularis & AY314827 & AY314850 & AY314809 \\
\hline Campanulotes compar & $\begin{array}{l}\text { Columba palumbus (plus two slides labelled } \\
\text { domestic pigeon) }\end{array}$ & AF320377 & AF189131 & AF348836 \\
\hline Chelopistes texanus & Ortalis vetula & AF320380 & - & AF348857 \\
\hline Coloceras clypeatum & Phapitreron amethystina & AF278662 & AY314851 & AF278644 \\
\hline Columbicola columbae & Columba livia & AF320385 & AF190415 & AF278620 \\
\hline Craspedonirmus immer & Gavia immer & AY314828 & AY314852 & AY314810 \\
\hline Craspedorrhynchus hirsutus & Buteo regalis & AY314829 & AY314853 & AY314811 \\
\hline Cuclotogaster hopkinsi & Francolinus africanus & AY314830 & AY314854 & AY314812 \\
\hline Degeeriella carruthi & Falco sparverius & - & - & AY314813 \\
\hline Degeeriella rufa & Falco berigora & AY314831 & AY314855 & - \\
\hline Discocorpus mexicanus & Crypturellus cinnamomeus & AF320392 & AF189133 & AF545695 \\
\hline Docophoroides brevis & Diomedea exulan, D. epomophora & AF320394 & AF396488 & AF396547 \\
\hline Echmepteryx hageni & NA & AY314832 & AY275323 & AY275298 \\
\hline Falcolipeurus marginalis & Cathartes aura & AY314833 & AY314856 & AY314814 \\
\hline Felicola subrostratus & Felis catus & AF320398 & - & AF545700 \\
\hline Geomydoecus craigi & Thomomys talpoides & AY314834 & AY314857 & AF348877 \\
\hline Goniocotes sp. & Phasianus colchicus & AY314835 & AY314858 & AY314815 \\
\hline Goniodes isogenos & Francolinus africanus & AF320404 & AY314859 & AF348851 \\
\hline Haematomyzus elephantis & Elephas maximus & AF320405 & AY314860 & AY314816 \\
\hline Haffneria grandis & $\begin{array}{l}\text { Catharacta (skua) skua, C. (skua) lonnbergi, } \\
\text { C. (skua) maccormicki }\end{array}$ & AF320406 & AF189135 & AF396553 \\
\hline Halipeurus pelagicus & $\begin{array}{l}\text { Oceanodroma castro, 0. leucorhoa, } \\
\text { Pelagodroma marina }\end{array}$ & AF320409 & AF189137 & AF396560 \\
\hline Harrisoniella densa & Diomedea immutabilis & AF320410 & AF396501 & AF396567 \\
\hline Ibidoecus bisignatus & Plegadis chihi & AY314836 & - & AY314817 \\
\hline Lipeurus caponis & Domestic chicken, Gallus gallus, G. gallus jabouillei? & AY314837 & AY314861 & AY314818 \\
\hline Naubates harrisoni & Puffinus assimilis & AF320432 & AF396504 & AF396571 \\
\hline Neopsittaconirmus circumfasciatus & Platycercus elegans & AY314838 & AY314862 & AY314819 \\
\hline Osculotes curta & Opisthocomus hoazin & AF348660 & AY314863 & AF348858 \\
\hline Oxylipeurus chiniri & Ortalis vetula & AF320436 & AF189140 & AF348872 \\
\hline Paraclisis confidens & Phoebastria nigripes & AF502566 & AF396511 & AF396579 \\
\hline Paragoniocotes sp. & Aratinga astec & AY314839 & AY314864 & AF348870 \\
\hline Pectinopygus sulae & Sula sula & AF320444 & AY314845 & AY314804 \\
\hline Perineus nigrolimbatus & Fulmarus (glacialis) glacialis & AF320448 & AF189143 & AF396589 \\
\hline Philoceanus robertsi & Oceanites oceanicus & AY314840 & AF396524 & AF396590 \\
\hline Philopterus sp. & Spizella pussilla & AY314841 & - & AY314820 \\
\hline Pseudonirmus gurlti & Daption capense & - & AF396525 & AF396591 \\
\hline Quadraceps sp. & Uria aalge & AF320458 & AF396527 & AF396599 \\
\hline Rallicola sp. & Aramides cajanea & AF320461 & AY314865 & AY314821 \\
\hline Saemundssonia stresemanni & Catharacta skua & AF320466 & AF189145 & AF396612 \\
\hline Strigiphilus crucigerus & Otus guatamalae & AF320468 & AY314866 & AF348866 \\
\hline Strongylocotes orbicularis & Crypterellus parvirostris & AY314842 & AY314867 & AY314822 \\
\hline Trabeculus hexakon & Puffinus griseus, P. gravis & AY179338 & AF396536 & AF396615 \\
\hline Trichodectes octomaculatus & Procyon lotor & AY314843 & AY314868 & AY314823 \\
\hline Vernoniella bergi & Guira guira & AY314844 & AY314869 & AY314824 \\
\hline
\end{tabular}




\section{Methods}

\section{Taxon sampling and specimen preparation}

Initial taxon choice was dictated by the genera sampled in Smith's (2001) morphological study. These capture a broad cross-section of ischnoceran taxonomic diversity as recognized by Eichler (1963). Taxon choice for the molecular data relied upon the availability of fresh and suitably preserved louse specimens. Louse DNA degrades quickly unless preserved in at least $95 \%$ ethanol or dried in a $-70{ }^{\circ} \mathrm{C}$ freezer, and consequently most specimens were freshly collected using ethyl acetate fumigation or related methods as described by Clayton \& Walther (1997). Where possible, conspecifics were chosen that matched those used by Smith. However, in many cases this was not possible and consequently suitable congenerics were substituted. A further eight genera sampled by Smith were excluded from the analysis, either because they were unavailable or failed to amplify during PCR.

Recent molecular data from the nuclear gene $18 \mathrm{~S}$ rRNA (Johnson \& Whiting 2002; Barker et al. in press) suggest that Ischnocera are monophyletic. This is also supported by morphology (Lyal 1985). Within Ischnocera, most authors consider the Trichodectidae (ischnoceran lice hosted by mammals) as basal, sister taxa to the avian Ischnocera (Philopteridae) (Blagoveshtchenskii 1956; Königsmann 1960; Mey 1994). This was used as justification for placing the root between the avian and mammalian ischnoceran lice in Smith's (2001) morphological study. Unfortunately, the highly derived morphology of Ischnocera means that assessing broader character homology with taxa outside the ischnoceran clade is extremely difficult. Consequently, to examine the validity of the trichodectid root used by Smith we include in our molecular dataset a single representative of the insect order Psocoptera (book lice), which is putatively the sistergroup to Phthiraptera (Lyal 1985; Barker et al. in press). A complete list of taxa used in this study along with their hosts is presented in Table 1 .

\section{Sequencing and morphology}

Total genomic DNA was extracted from individual lice by carefully removing the head from the body and placing both parts in digestion buffer from a Qiagen tissue extraction kit. Digestion proceeded for $56 \mathrm{~h}$ at $55^{\circ} \mathrm{C}$, at which point the head and body were removed and prepared for mounting in Canada balsam on a microslide as a voucher for subsequent species identification. Vouchers are deposited in the Price Institute for Phthirapteran Research (PIPeR) at the University of Utah, Salt Lake City; the Illinois Natural History Survey, Champaign, Illinois; and the louse collections in the Page Lab at the University of Glasgow, Scotland, UK. DNA extraction was completed using the manufacturer's protocols (Qiagen).
For each taxon we amplified portions of the following genes using PCR: (1) A 347-bp fragment of the nuclear gene EF1- $\alpha$ using the primers EF1-For3 and Cho10 (Danforth \& Ji 1998); (2) a 386-bp fragment of the COI mitochondrial gene using the primers L6625 and H7005 (Hafner et al. 1994); and (3) a fragment corresponding to domain III of the $12 \mathrm{~S}$ rRNA mitochondrial gene (265-457 bp) using the insect specific primers 12 Sai and 12Sbi (Simon et al. 1994). A subset of the EF1- $\alpha$ sequences was taken from Cruickshank et al. (2001) and supplemented with sequences from 27 additional taxa. PCR conditions included an initial denaturation step of 2 min at $94^{\circ} \mathrm{C}$, followed by 35 cycles of a 30 second denaturation step at $94^{\circ} \mathrm{C}, 30 \mathrm{~s}$ annealing at $46^{\circ} \mathrm{C}$, and $30 \mathrm{~s}$ extension at $72^{\circ} \mathrm{C}$, with a final extension step of $7 \mathrm{~min}$ at $72^{\circ} \mathrm{C}$. PCR products were gel purified using a Qiaquick Gel Extraction Kit (Qiagen) or a Qiagen PCR purification kit. We performed cycle DNA sequencing with Taq FS or AmpliTaq DNA polymerase using either ABI dRhodamine dye terminators or ABI Prism BigDye Terminators according to manufacturer's instructions. Sequencing products were ethanol precipitated and run on an ABI 373 or 377 Stretch automated sequencing machine. Both strands were sequenced for all taxa.

All morphological characters and character states used in this study were taken from Smith's (2001) analysis of ischnoceran phylogeny. All taxa listed in his appendix I were included with the exception of the congeneric taxa that were unmatched in the molecular dataset and the following taxa for which suitable material for the molecular work was unavailable (Damalinia crenelata, Lagopoecus affinis, Pelmatocerandra setosa, Podargoecus strigoides, Splendoroffula ruwenzorornis, Sturnidoecus sturni, Syrrhaptoecus falcatus, Upupicola upupae).

\section{Alignment and data availability}

Complimentary chromatograms were reconciled and aligned using Sequencher 3.1 (GeneCodes) and the sequences were deposited in LouseBase, an online specimen and data management tool for lice (http://r6-page.zoology.gla.ac.uk/ Lousebase/2/). This relational database was used to manage all the associated species data, determinations, host information, and assisted in resolving the most appropriate taxon sets for final alignment and analysis. Datasets for the COI and EF1- $\alpha$ sequences were manually aligned using SE-AL 2.09 (http://evolve.zoo.ox.ac.uk/software/Se-Al/). These alignments were unambiguous, with the exception of two large introns that were deleted from the EF1- $\alpha$ outgroup sequence $E c h$ mepteryx. By contrast the alignment for the mitochondrial $12 \mathrm{~S}$ gene was particularly problematic. Previous studies have shown that louse $12 \mathrm{~S}$ rRNA secondary structure is particularly variable and difficult to align (Page et al. 2002). Initial attempts at aligning the complete dataset with ClustalX (Thompson et al. 1997) and Malign (Wheeler \& Gladstein 1995) dramatically failed when compared to smaller reference 
alignments constructed by Page et al. (2002) based on secondary structure. Failure of these partially automated methods is likely to be due to the considerable sequence length variation between louse taxa. This variation reflects frequent insertion and deletion events and varying lengths of stems and loops between core helices. Consequently, the $12 \mathrm{~S}$ dataset was aligned with the aid of the programme SSE (Secondary Structure and Evolution, developed by Roderic Page, University of Glasgow) and all loop regions were excluded from subsequent analyses. Initial secondary structures were computed using the program RNAlign (Corpet \& Michot 1994) using a server constructed by Page (2000) that aligns a user-supplied sequence to a reference alignment of five insect sequences and the Page (2000) secondary structure. The server returns a secondary structure for the user's sequence, and an alignment of that sequence to the five reference sequences. Secondary structures were drawn using RnaViz 1.0 (DeRijk \& DeWachter 1997). The complete data matrix and alignment is available from TreeBase (http://www.treebase.org/) under study accession number SN1481. In addition, individual sequences are deposited in GenBank (see Table 1) and LouseBase (http://r6-page.zoology.gla.ac.uk/Lousebase/2/).

\section{Phylogenetic analysis}

Base frequencies and uncorrected pairwise nucleotide frequencies were calculated for each gene fragment using PAUP* (Swofford 2002) version 4.0b10. A chi-squared test of homogeneity of base frequencies was also performed using PAUP*4.0. MacClade 3.07 (Maddison \& Maddison 1992) was used to estimate the frequency distribution of the observed number of substitutional changes per character for each gene and for each codon position of the protein-coding genes.

Generic louse relationships were inferred from parsimony and maximum-likelihood (ML) analyses implemented in PAUP 4.0 and Bayesian inference implemented in MrBayes 2.0 (Huelsenbeck \& Ronquist 2001). Data were divided into the following partitions: (a) morphology; (b) protein coding genes; (c) all DNA data, and (d) DNA and morphological data. Due to problems amplifying particular genes, a single gene sequence was missing from the combined analyses for a small number of taxa. To examine the impact of these missing data, analyses were also conducted with a restricted ischnoceran dataset confined to the 39 taxa for which a complete set of sequences was available.

The homogeneity of the signal from each of the three data partitions was assessed by conducting a series of Incongruence Length Difference (ILD) tests (Farris et al. 1994b) using 100 replicates for each analysis as implemented in PAUP*4.0, with invariant characters removed (Cunningham 1997). Multiple pairwise tests were also performed between each pair of genes (three tests) and between the combined molecular and morphological data (one test).
Incorrect estimates of phylogeny can occur for a variety of reasons - usually because the assumptions implicit in our models of character evolution are violated by the data. Functional constraints such as the secondary structure of RNA molecules (Jow et al. 2002), or taxon specific factors resulting in within site variation (heterotachy) (Lopez et al. 2002) are examples of just two phenomena that may confound many methods of phylogenetic analysis. Whilst it is beyond the scope of this paper to examine every nuance of character evolution that can yield inaccurate estimates of phylogeny, we can crudely explore whether our data violate some of these assumptions. Nonstationarity (variations in substitution patterns across a phylogeny) has been reported in previous studies based on louse EF1- $\alpha$ sequences (Cruickshank et al. 2001). This can result in differences in base composition among lineages (Hasegawa \& Hashimoto 1993; Lockhart et al. 1994) or differences in the distribution of variable sites (covariotide/covarion pattern of changes, Lockhart et al. 1996, 1998). Using the program Statio (Rzhetsky \& Nei 1995) we analysed a dataset that incorporated all taxa for which a complete set of protein coding genes was available. Stationarity was rejected overall $(P<0.005)$, and for third base positions $(P<0.005)$, but not for first $(P=0.861)$, and second $(P=1.000)$ positions, i.e. base composition differs significantly in different parts of the tree. This result suggests that methods which can correct for nonstationarity (e.g. LogDet distance based methods) should also be explored.

Each data partition was analysed both separately and combined, using a combination of discrete (parsimony, likelihood plus Bayesian) and distance (LogDet) based approaches, with the exception of the morphological partition (and combinations thereof) to which only parsimony could readily be applied. All parsimony-based tree searches were performed using TBR branch swapping with 100 random addition sequence replicates using a random starting tree and implemented in PAUP* 4.0. In all likelihood analyses the best model of DNA substitution was selected by ModelTest 3.0 (Posada \& Crandall 1998) using the Akaike Information Criterion (AIC; Akaike 1974). A ML heuristic search (options: AS-IS addition sequence and SPR branch swapping) was run under the likelihood settings (empirical base frequencies, proportion of invariable sites and gamma shape parameter) estimated with ModelTest 3.0. Bayesian analyses were performed with MrBayes 2.0 on the molecular datasets. Analyses were partitioned by codon position and gene (i.e. seven partitions for the combined, COI, EF1- $\alpha$ and $12 \mathrm{~S}$ analyses and six for the combined COI and EF1- $\alpha$ ). Rate heterogeneity was set according to a gamma distribution with six rate categories (GTR model) for each data partition. Four chains were analysed for 500000 generations with a sampling frequency of 100. Stationarity was achieved before $c .100000$ generations and these were ignored as 'burnin' trees before the trees 
from each Markov chain were combined. Posterior probabilities were determined for tree topology, branch length and model parameters.

Support for nodes on the likelihood and parsimony trees were evaluated by nonparametric bootstrapping (Felsenstein 1985 ) with 100 (ML) or 1000 (MP) replicates and NNI branch swapping (ML) or TBR swapping (MP). Decay indices, also known as Bremer support values (Bremer 1988) were calculated for those datasets analysed by parsimony with the assistance of AutoDecay (Eriksson 1997) using 100 random addition sequence replicates per constraint and NNI branch swapping. Where appropriate, we also measured the skew (g1) in the distribution of cladogram lengths (Huelsenbeck 1991) based on 10000 randomly generated trees as an indicator of phylogenetic signal.

We also used parametric bootstrap analysis to test the monophyly of the circumfasciate and noncircumfasciate clades highlighted by the morphological data. This technique is preferable to other methods of tree comparison in that it is less prone to type II statistical error (Goldman et al. 2000). Model trees were estimated from the Bayesian analyses with taxa constrained to be compatible with a hypothesis of monophyly for both the circumfasciate and noncircumfasciate lice, and for the circumfasciate taxa alone (loosest constraint possible). For each model tree (with branch lengths) we used the model of sequence evolution and parameters estimated by ModelTest to generate 100 simulated replicate datasets of the same size as the original one. Sequence evolution was modelled using Seq-Gen (Rambaut \& Grassly 1997). Two heuristic searches were conducted on each replicate dataset using NNI branch swapping: once to find the overall optimal tree and again to find the best tree compatible with the constraint used to generate the model tree. Scores of these likelihood trees were then used to construct an expected distribution of likelihood differences under the null hypothesis being tested. Significance of the test statistic (the difference in log-likelihood values between the constrained and optimal trees) was assessed by direct comparison to the expected distribution (Hillis et al. 1996).

Topological congruence between optimal trees from each dataset was investigated using a combination of measures. Estabrook's (1992) measure of positional congruence as implemented in RadCon 1.15 (Thorley \& Page 2000) was used to determine the measure of agreement among a set of trees, about the position of the leaf. In rooted trees this is the proportion of resolved triplets that explicitly agree about the position of a taxon, and can be extended to consider overall congruence between trees by averaging the sum of explicit agreement values (termed EA similarity) for each taxon. For example, comparison between two identical bifurcating trees will yield an EA value of 1, since all triplets between trees for each taxon explicitly agree. As trees become progressively dissimilar, fewer triplets will be in explicit agreement and consequently EA values will fall, reaching 0 in the case where two bifurcating trees share no triplets in common. A particular advantage of this technique is that it can be used to compare topologies with taxon sets that do not entirely match. Thus subtrees of one dataset can be compared to more thoroughly sampled topologies from another.

A broad comparison of the topologies from each optimal tree was obtained via an ordination of partition metric scores. This metric provides a measure of the number of clusters (clades) unique to one of the pair of trees being considered; thus the larger the score, the greater the dissimilarity between the trees. Partition metric scores for each pairwise comparison were calculated between every optimal tree, regardless of the data source (i.e. molecules or morphology) or method of analysis (parsimony, likelihood or Bayesian) using Component (Page 1993). These scores were analysed using principal coordinate analysis and the results from the first two principal coordinates were plotted. This can be used to explore the tree space occupied by each tree, partitioned by the data from which the tree was derived and the method of analysis used to infer phylogeny.

\section{Results}

\section{Data characteristics}

The complete dataset including morphological data contained 1019 aligned characters of which 673 were variable and 573 were parsimony informative. Within the molecular data, 151 of the 348 bp (43\%) for the EF1- $\alpha$ gene fragment were variable, and 128 of these (36\%) were parsimony informative. COI contained a larger fraction of variable sites (241 of $387,62 \%$ ) and a much larger fraction of these were parsimony informative. These statistics were even greater for $12 \mathrm{~S}$, with $80 \%$ of the 146 unambiguously aligned characters parsimony informative.

There is little overall base composition bias, although the pattern varies somewhat for each codon position in the protein coding genes (Table 2). The Chi-squared test of homogeneity of base frequencies across taxa resulted in

Table 2 Average base frequencies for each molecular dataset.

\begin{tabular}{llllll}
\hline \multirow{5}{*}{$\begin{array}{l}\text { Codon } \\
\text { position }\end{array}$} & A & C & G & T \\
\cline { 3 - 6 } & 1st & 27.5 & 19.2 & 34.6 & 18.7 \\
\hline EF1- $\alpha$ & 2nd & 31.6 & 27.6 & 15.9 & 24.8 \\
& 3rd & 17.6 & 37.9 & 20.6 & 23.9 \\
& 1st & 30.8 & 9.8 & 33.2 & 26.2 \\
COI & 2nd & 14.5 & 20.2 & 20.3 & 44.9 \\
& 3rd & 31.5 & 10.9 & 15.3 & 42.2 \\
\multirow{2}{*}{125} & & 28.3 & 18.2 & 23.9 & 29.4 \\
\hline
\end{tabular}




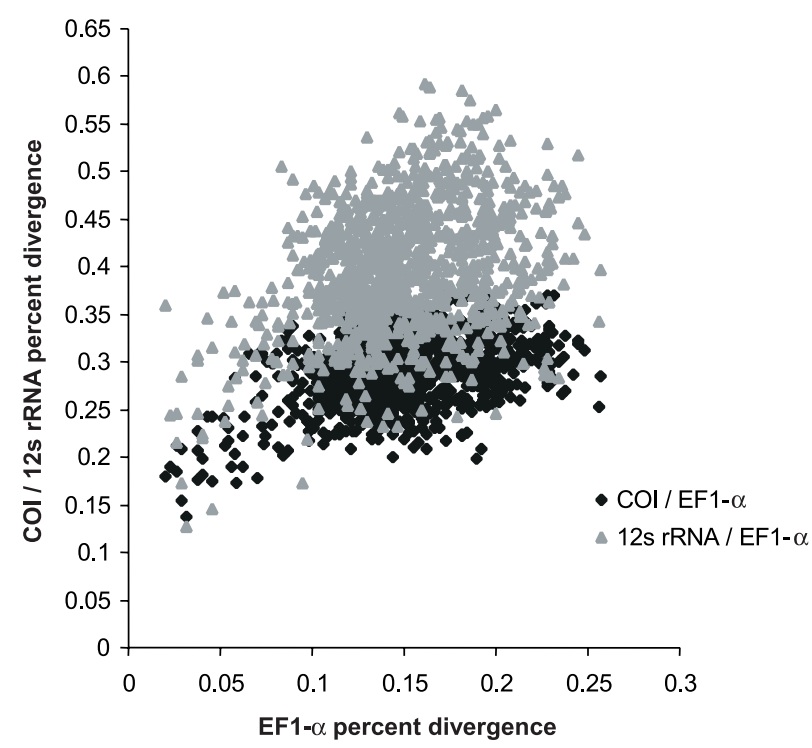

Fig. 3 Plots of overall pairwise percentage divergence between EF1$\alpha$, COI and 12S rRNA.

$P$-values of $1.00,1.00$ and $<0.01$, respectively, for 1 st, $2 \mathrm{nd}$, and 3 rd positions of the EF1- $\alpha$ and COI sequences and 0.99 for $12 \mathrm{~S}$, indicating no significant heterogeneity except at third positions. Comparisons of uncorrected pairwise divergences indicate that COI evolves approximately 12 times faster than EF1- $\alpha$ (Fig. 3). This estimate is slightly higher than those generated from previous studies using louse EF1- $\alpha$ and COI sequences (Johnson et al. 2001a,b) but is considerably lower than the $>100: 1$ estimate suggested by Johnson et al. (2003). The higher value attempts to correct for phylogenetic correlation and saturation, and is likely to be considerably closer to the actual relative rate. Uncorrected comparisons between COI and $12 \mathrm{~S}$ suggest that both genes are evolving at an approximately similar rate. However, the exclusion of the unalignable $12 \mathrm{~s}$ rRNA loop regions and the small size of remaining stem fragments make meaningful comparisons difficult. Uncorrected sequence divergences between louse species ranged between 2.0 and $25.7 \%$ for EF1- $\alpha, 13.7$ and $38.3 \%$ for COI, and between 12.8 and $59.2 \%$ for $12 \mathrm{~s}$. These values are surprisingly high relative to divergences within other insect groups spanning similar levels of taxonomic diversity.

\section{Data quality and hierarchical structure}

The small size of the individual gene fragments, their rapid rate of evolution and high rates of sequence divergence pose many challenges for most methods of phylogenetic analysis. Under these circumstances it seems reasonable to question their very suitability for phylogenetic study. Several measures of data quality and hierarchical structure such as the PTP test
(Archie 1989; Faith \& Cranston 1991) and g1 statistic (Huelsenbeck 1991) have been proposed, amid much controversy over their suitability for this task. Each dataset presented here passed the PTP and left-skewness (g1) test using 10000 permuted datasets or 10000 randomly generated trees, respectively $(P<0.05)$. This is taken to indicate that the data matrices contain significantly more hierarchical structure than randomized/random data (Faith \& Cranston 1991; Hillis \& Huelsenbeck 1992). However, several phylogeneticists dispute this interpretation, and both methods have been discredited by some systematics. In particular, the PTP test has been strongly criticized, since it is believed to be subject to high type 1 and type 2 error rates (Källersjö et al. 1992; Farris et al. 1994a; Carpenter et al. 1998), although Wilkinson et al. (2002) have recently shown this is incorrect, at least for type 1 .

Two methods of assessing data quality that are seldom used despite having been available for some time are split decomposition (Bandelt \& Dress 1992) and likelihood mapping (Strimmer \& Haeseler 1997). Split decomposition transforms phylogenetic data into a set of weakly compatible splits that can be represented by a so-called splits graph. Unlike a phylogenetic tree, split decomposition does not enforce a tree-like (bifurcating) structure, so reticulations in the resulting network can be interpreted as evidence for conflicting phylogenies. Further, the degree of structure in the splits graph can provide a good indication of how tree-like a given dataset is. Likelihood mapping uses a very different approach but its goal of visualizing the phylogenetic content of a set of aligned sequences is similar. Likelihood values are computed for the three possible tree topologies of every quartet in a dataset and represented as a point inside an equilateral triangle. This triangle is partitioned into different regions corresponding to the strength of the phylogenetic signal. Points plotted toward the centre represent a situation whereby each of the possible topologies is more-or-less equally likely. This region represents star-like evolution. Regions close to the apices of the triangle represent well-resolved phylogenies, i.e. highly structured data, while regions between the apices correspond to areas where it is difficult to distinguish between two of the three trees. The final distribution of points reveals the degree of hierarchical structure or tree-likeness present in the dataset.

Split decomposition and likelihood mapping were applied to each gene fragment using the programs Splits-Tree 2.4 (Huson 1998) and Tree-Puzzle 5.0 (Strimmer \& Haeseler 1997) (Fig. 4). A subset of taxa representing the 39 genera that had a complete dataset for each gene was chosen for these analyses. Results of independent maximum likelihood analyses using optimal models determined by ModelTest (Posada \& Crandall 1998) are also included in this figure. Note that branch lengths are drawn to the same scale, 
A. EF1- $\alpha$

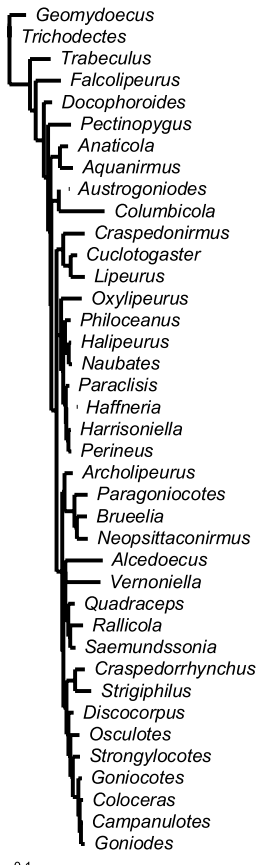

$\underline{0.1}$
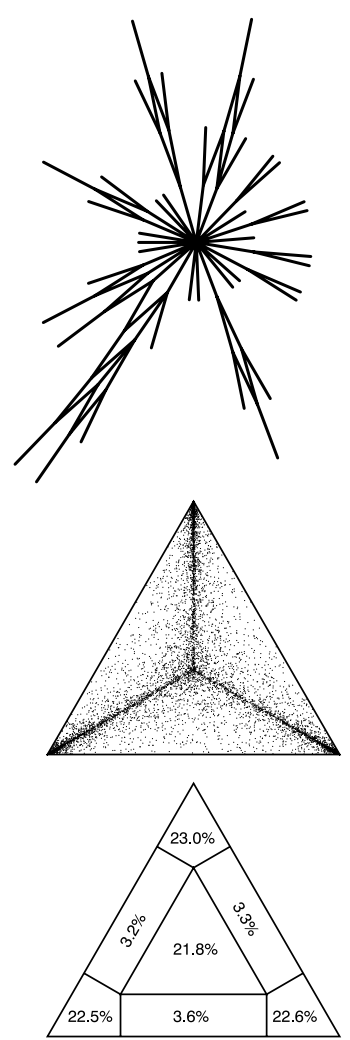

B. COI

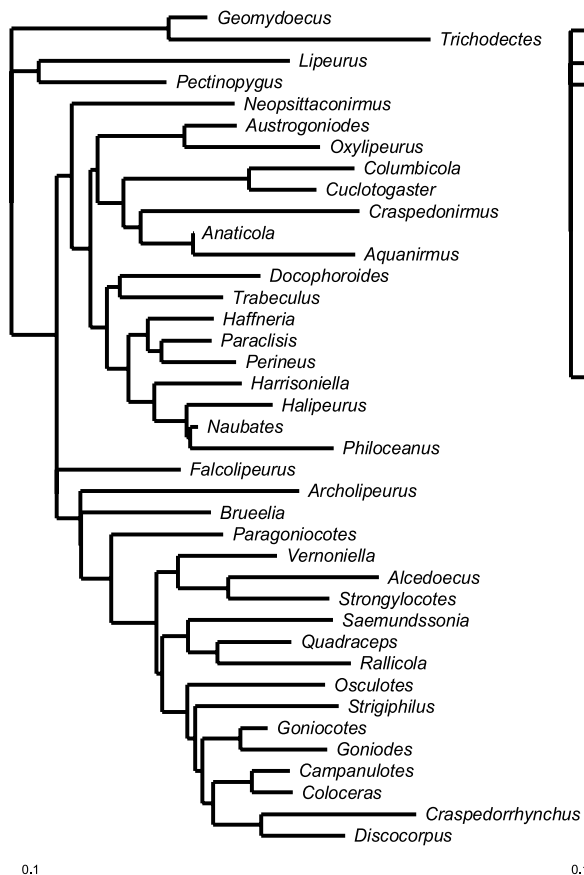

0.1
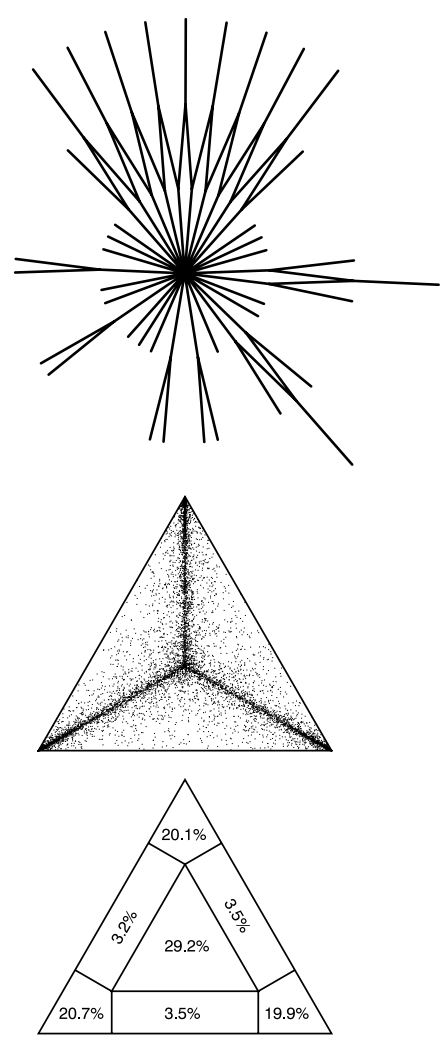

\section{12S sRNA}

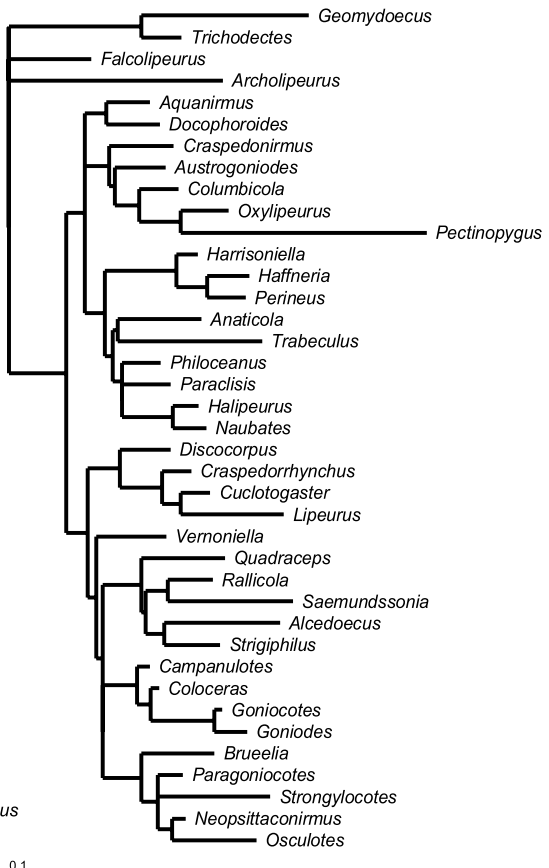

$\underline{0.1}$
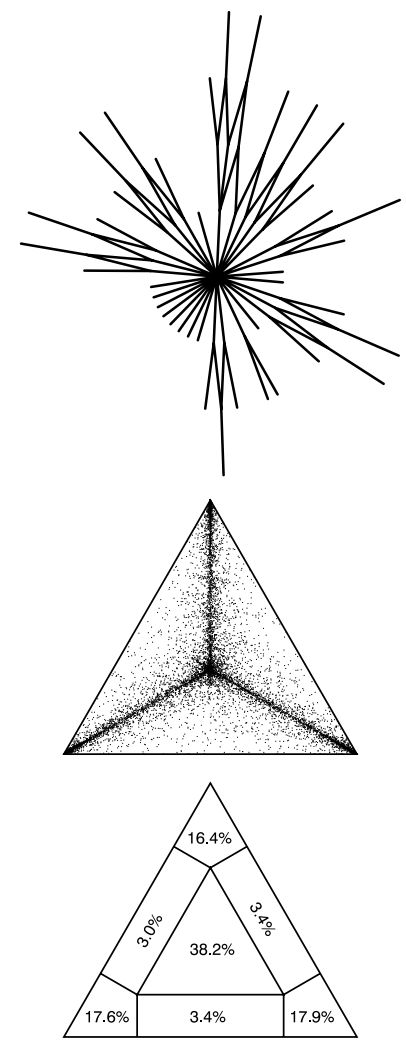

Fig. 4 Optimal likelihood trees, Splits Trees, and likelihood maps for the three gene fragments (EF1- $\alpha$, COI and 12S rRNA) used in the analysis. Branch lengths are drawn to the same scale on the likelihood trees, and Splits Trees were refined over maximal number of quartets and drawn with equal edge lengths. 
illustrating the different rates of sequence divergence between genes.

The least tree-like of the three gene fragments is $12 \mathrm{~S}$ rRNA with just $52 \%$ of the quartets from the likelihood mapping analysis mapped into regions of the triangle representing well resolved phylogenies. This is also illustrated by the splits-tree, which is drawn as a near star phylogeny. It is likely that this poor result partly reflects the very short aligned sequence length (just $146 \mathrm{bp}$ ). Mitochondrial COI performs little better, with a little over $60 \%$ of the quartets mapped into the strongly tree-like regions. The splits graph highlights more hierarchical structure to the dataset than for $12 \mathrm{~s}$. However, the large number of reticulations in the network suggests that much of the data are conflicting. EF1- $\alpha$ is by far the most structured of all three datasets, with almost $70 \%$ of the quartets mapped onto strongly tree-like regions, and a more structured splits-tree. However, the very short internal branch lengths from the ML analysis suggest that much of the phylogenetic signal within this dataset is likely to be weak.

\section{Morphological and molecular analyses}

Maximum parsimony searches of the morphological data using 100 random addition sequence replicates produced 171 equally parsimonious trees on two tree islands (length 812, $\mathrm{CI}=0.32, \mathrm{RI}=0.61)$. A strict consensus of these is shown in Fig. 5A. Despite the large number of equally parsimonious trees, the consensus is reasonably resolved, and almost entirely congruent with the larger phylogeny originally presented by Smith (2001). The basal split between the circumfasciate and noncircumfasciate head types is maintained with Bremer support values of 11 and 9, respectively. Less resolution is evident towards the tips of this consensus tree. This is largely a result of the reduced taxon sampling within particular clades required to make them compatible with the available molecular data. For example, resolution is particularly poor in the Saemundssonia- and Philopterus-complex (sensu Smith 2001), and not surprisingly these correspond to clades that were particularly poorly sampled in this dataset.
Unweighted parsimony analyses of the molecular data performed poorly with respect to bootstrap values and levels of resolution (Fig. 5A-D). This can be attributed to the large rate differences, nonstationarity of base composition and short internal nodes within each reconstruction. These conditions are exactly those under which parsimony is expected to perform particularly badly, since levels of homoplasy between and within each dataset are highly variable. Particularly striking is the lack of agreement between these trees, each sharing just 12 nodes in common. Significantly, all trees obtained from parsimony analyses lack support for a single split between the two head types defined by the morphological data. All trees support the monophyly of the Trichodectidae with bootstrap values ranging from 75 to 92 . However, none of the parsimony analyses of the molecular datasets (or partitions thereof) support the monophyly of the Philopteridae. In each case the Trichodectidae were within this clade, either close to the base of the Philopteridae, or in the case of the combined molecular and morphological dataset, deeply embedded within this clade.

Congruence amongst the molecular phylogenies obtained from the likelihood and Bayesian analyses is much higher (Fig. 6) and is considerably greater than those from the parsimony analyses. This is illustrated by the positional congruence values shown in Table 3 that show the average stability of all taxa relative to others between two trees. The Bayesian and likelihood trees from the combined analysis share 33 common nodes, whilst the equivalent trees restricted to the coding genes share 26. All molecular trees support the monophyly of the mammalian Ischnocera (family Trichodectidae) but in only one case (the Bayesian analysis of the coding genes) was the monophyly of the Philopteridae (from birds) supported. All other trees place the Trichodectidae close to the base but within the Philopteridae, and it is clear that this dataset struggles to resolve some of the deeper nodes in the tree, particularly with respect to the Trichodectidae and three key ischnoceran taxa (see Discussion). This is almost certainly a result of the high level of saturation present within

Table 3 Average positional congruence values (EA similarities) between trees. Abbreviations: P, parsimony; L, likelihood; B, Bayesian; LD, LogDet.

\begin{tabular}{|c|c|c|c|c|c|c|c|c|c|}
\hline & $\begin{array}{l}\text { Morphology } \\
\text { (P) }\end{array}$ & $\begin{array}{l}\text { All data } \\
\text { (P) }\end{array}$ & $\begin{array}{l}\text { Coding genes } \\
\text { (P) }\end{array}$ & $\begin{array}{l}\text { All molecular } \\
\text { (P) }\end{array}$ & $\begin{array}{l}\text { All molecular } \\
\text { (L) }\end{array}$ & $\begin{array}{l}\text { Coding genes } \\
\text { (L) }\end{array}$ & $\begin{array}{l}\text { All molecular } \\
\text { (B) }\end{array}$ & $\begin{array}{l}\text { Coding genes } \\
\text { (B) }\end{array}$ & $\begin{array}{l}\text { All molecular } \\
\text { (LD) }\end{array}$ \\
\hline Morphology (P) & - & - & - & - & - & - & - & - & - \\
\hline All data $(\mathrm{P})$ & 0.4025 & - & - & - & - & - & - & - & - \\
\hline Coding genes $(\mathrm{P})$ & 0.4082 & 0.6238 & - & - & - & - & - & - & - \\
\hline All molecular (P) & 0.4884 & 0.8085 & 0.7342 & - & - & - & - & - & - \\
\hline All molecular (L) & 0.5140 & 0.7233 & 0.6548 & 0.8402 & - & - & - & - & - \\
\hline Coding genes $(\mathrm{L})$ & 0.5172 & 0.6956 & 0.6496 & 0.8057 & 0.9426 & - & - & - & - \\
\hline All molecular (B) & 0.5236 & 0.7346 & 0.6437 & 0.8226 & 0.9204 & 0.8799 & - & - & - \\
\hline Coding genes (B) & 0.5550 & 0.6253 & 0.6242 & 0.7296 & 0.7987 & 0.8048 & 0.8237 & - & - \\
\hline All molecular (LD) & 0.5552 & 0.6937 & 0.6345 & 0.8055 & 0.7529 & 0.7300 & 0.7349 & 0.7166 & - \\
\hline
\end{tabular}




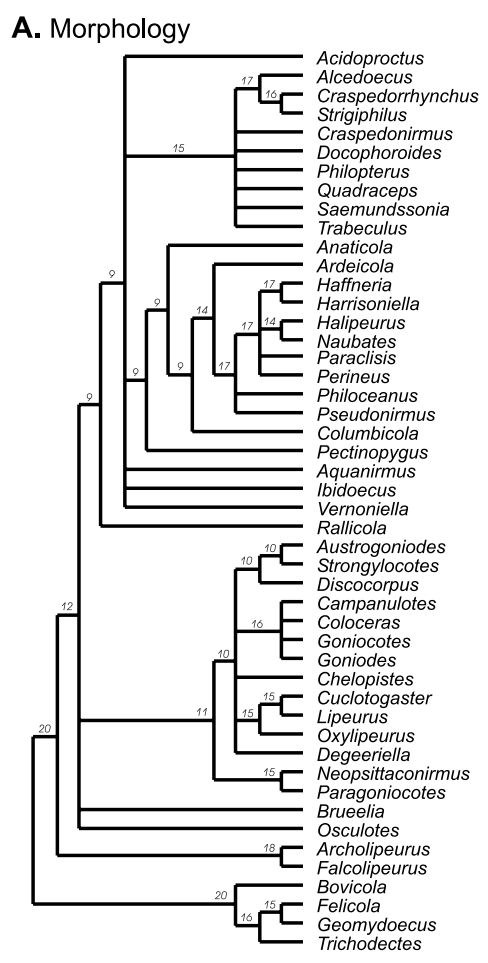

C. All molecular data

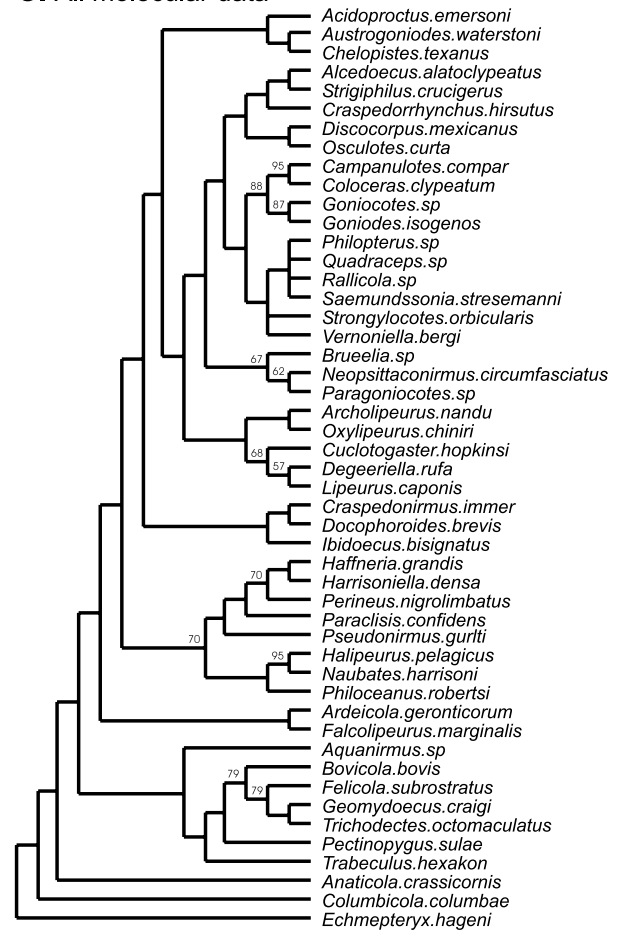

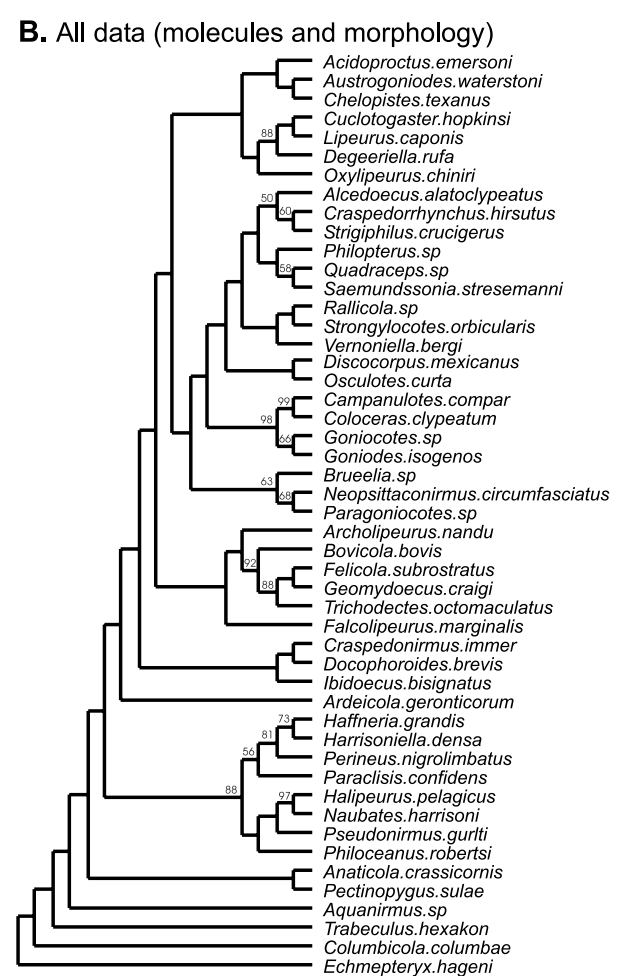

D. EF1- $\alpha \&$ COI

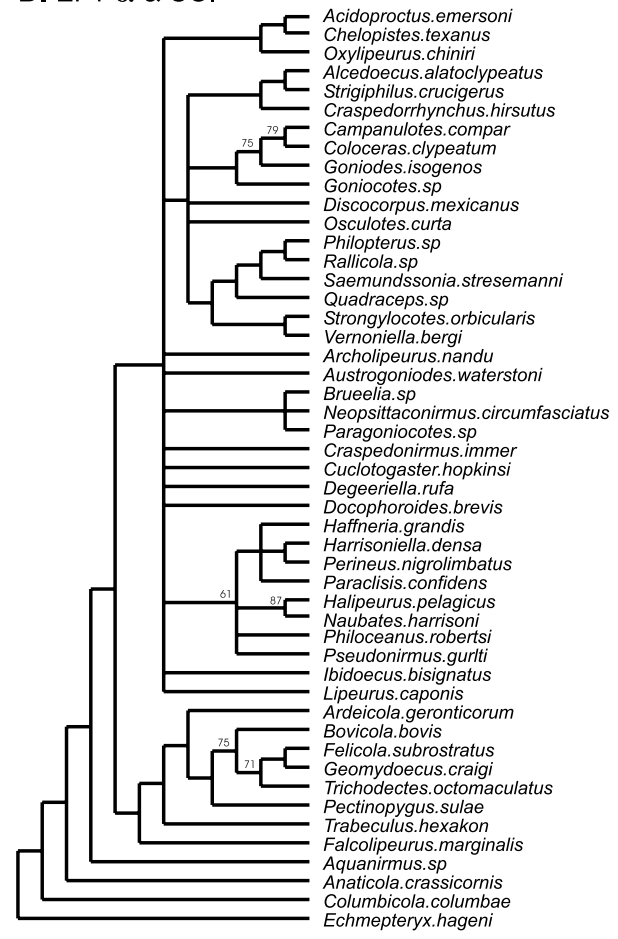

Fig. 5 A-D. Most parsimonious topologies estimated from each data partition. -A. Morphological data; strict consensus of 171 equally parsimonious trees in two tree islands $(\mathrm{L}=812, \mathrm{CI}=0.32, \mathrm{RI}=0.61)$. - B. Combined molecular and morphological data; single tree from one island $(\mathrm{L}=6045, \mathrm{CI}=0.21, \mathrm{RI}=0.37)$. - C. All molecular data; strict consensus of five trees from a single tree island $(\mathrm{L}=5094, \mathrm{CI}=0.20$, $\mathrm{RI}=0.33)$. - D. Protein coding genes; strict consensus of 23 trees in three islands $(\mathrm{L}=3914, \mathrm{CI}=0.19, \mathrm{RI}=0.33)$. Numerals above the nodes indicate Bremer support values (morphological data only, italics) and bootstrap values. 


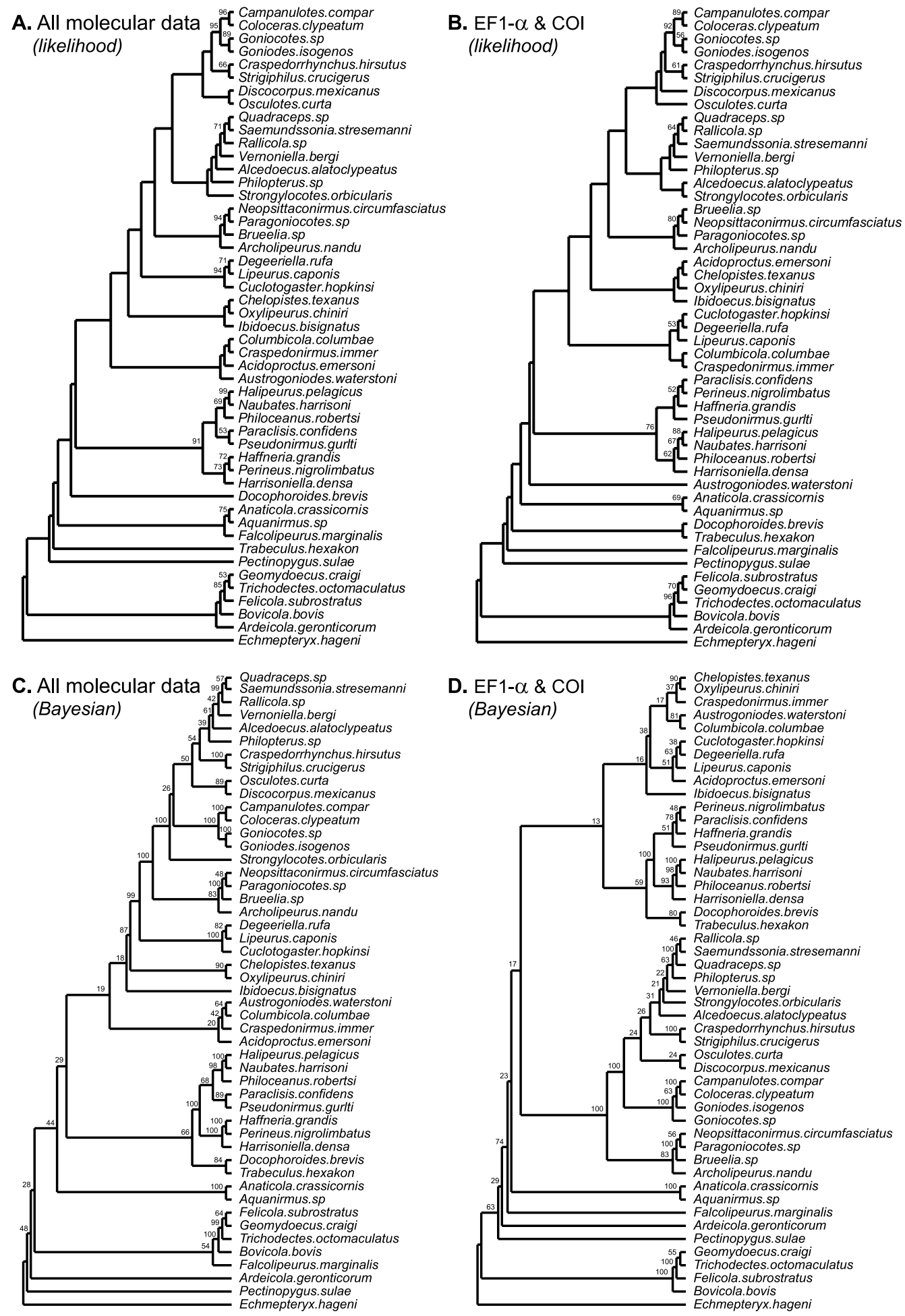

Fig. 6 A-D. Likelihood and Bayesian topologies estimated from partitions of the molecular data. -A. Optimal tree estimated from all molecular data; GTR + G + I model (Ln likelihood = -19337.4). - B. Optimal tree estimated from protein coding sequences; GTR + G + I model $($ Ln likelihood $=-14972.7)$. - C. Majority rule consensus from Bayesian inference analysis of all molecular data. $-D$. Majority rule consensus from Bayesian inference analysis of all protein coding sequences. All Bayesian analyses were partitioned by codon position and gene. Numerals above the nodes indicate bootstrap support (likelihood) or posterior probability values (Bayesian analysis). 
Fig. 7 A, B. Results of the parametric bootstrap analysis. Model trees were constructed for each hypothesis by conducting maximum likelihood searches with taxa forced to the constraint tree (shown inset). The distributions of the difference in likelihood scores between the optimal trees and the best trees that fit the constraint are shown for 100 simulations for each hypothesis. In each case, the difference in score between the model and observed trees for the original data (arrows) was considerably greater than expected if the corresponding hypothesis were true. Thus, both hypotheses are rejected at $P<0.01$. -A. Test of monophyly of the circumfasciate lice sensu Smith (2001). - B. Test of monophyly of the circumfasciate and noncircumfasciate lice sensu Smith (2001).

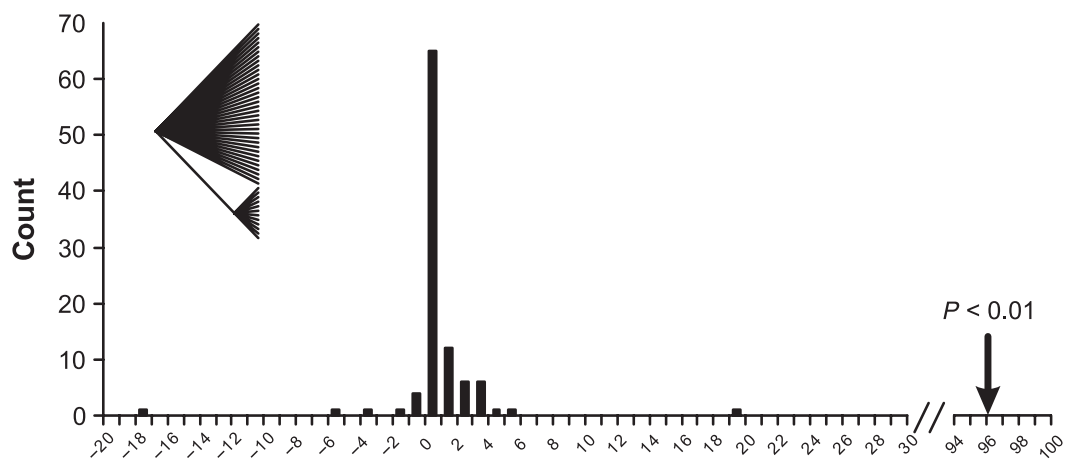

B. Monophyly of circumfasciate \& non-circumfasciate taxa (sensu Smith, 2001)

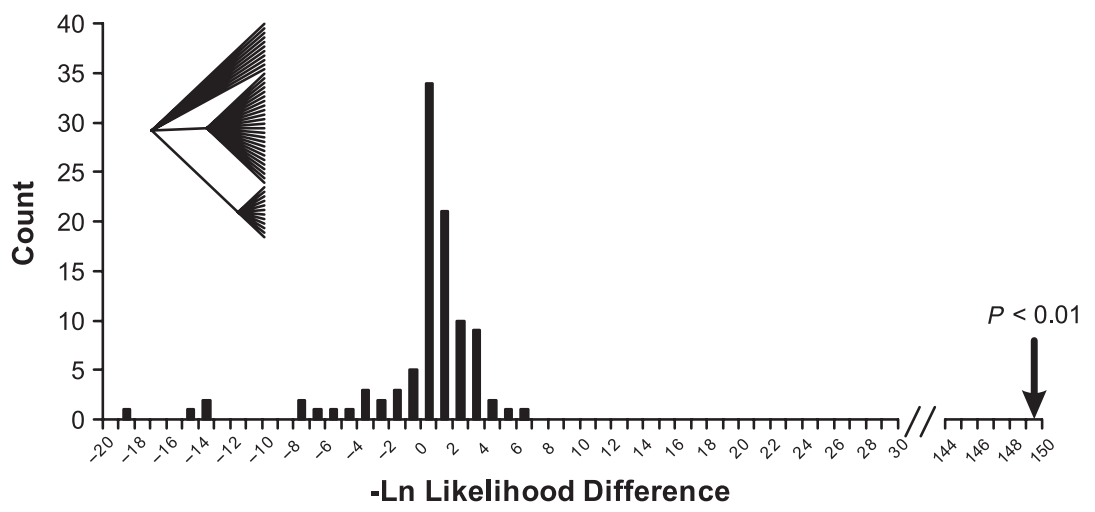

the gene fragments examined. Nevertheless, the likelihood, Bayesian and LogDet trees (latter not shown) are strikingly incongruent when compared to the morphological tree. Notably, these trees again fail to distinguish the key clades delimited by head morphology. The LogDet tree in particular contains some unusual terminal groups that are unique to that tree.

\section{Tests of monophyly}

Parametric bootstrap analysis of the molecular data clearly rejects the null hypotheses of monophyly for both the circumfasciate and noncircumfasciate clades predicted by morphology $(P<0.01$; Fig. 7). Under the constraint of circumfasciate monophyly, the loosest constraint possible in this analysis, the $\log$ likelihood difference between the simulated datasets with and without the constraint ranges from -18 to +19 . However, the observed difference in $\log$ likelihood for the actual dataset was 96 . Thus the probability of observing a difference of this magnitude (if the null hypothesis were true) is considerably less than $1 \%$. Indeed, the fact that in many of the simulations the constrained data had a better likelihood score than the unconstrained data, reflects the very short internal branch of the original constrained tree from which the simulated data was generated.

\section{Topology based tree comparisons}

The ordination of partition metric scores calculated between each optimal tree is shown in Fig. 8. Each point corresponds to a single optimal tree and the distance between each point provides a visual representation of the topological difference between each phylogeny. The shading corresponds to the original data source and highlights the topological disparity between the morphological and molecular data. Two clusters of morphological trees are present, corresponding to the two tree islands of 171 equally parsimonious trees. These clusters are distinct from the combined molecular trees occupying very different space in the ordination. The maximum pairwise difference within the molecular trees (66) is considerably greater that the maximum pairwise distance within the morphological trees (38). This suggests that the molecular data are particularly sensitive to the data partition (i.e. coding or combined) and/ or phylogenetic method used in the analysis. The total evidence tree ( $\boldsymbol{\Delta}$ in Fig. 8) combining both the molecular and morphological data is topologically more similar to the optimal molecular trees than it is to those derived from morphology.

\section{Conflict and congruence tests}

The $P$-values from the incongruence length difference tests revealed significant incongruence $(P<0.05)$ in all but one 


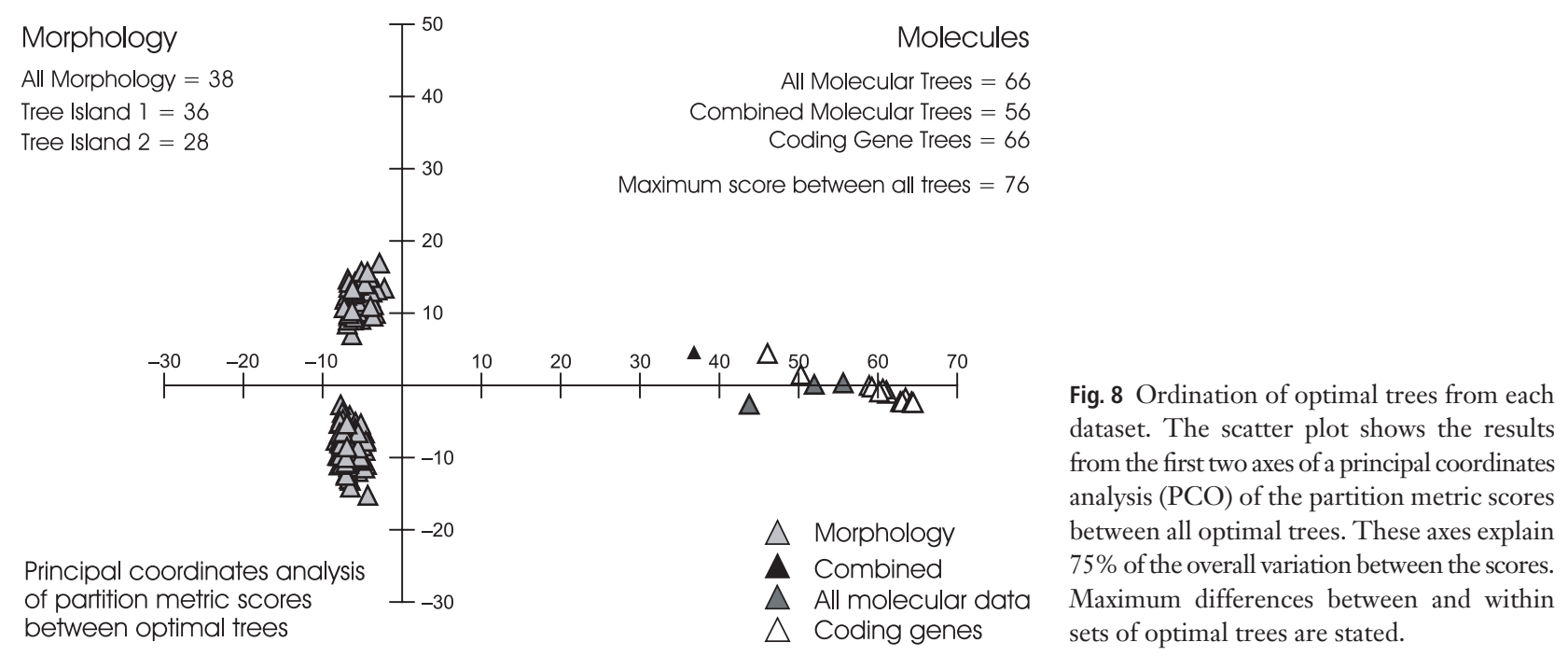

of the paired comparisons. Only comparison between the COI and $12 \mathrm{~S}$ gene fragment proved not significant $(P=0.16)$. This may reflect the fact that they are both part of the mitochondrial genome and thus inherited as a single linkage group.

Comparisons between trees based on the positional congruence values (Table 3 ) provide a more mixed picture. Congruence is greatest between the likelihood and Bayesian analyses of the molecular data with similarity values ranging from 0.80 to 0.94 . These comparisons contained four of the top five highest congruence values and only the comparison between the combined likelihood and combined parsimony analysis also falls within this range. These trees are also broadly similar to the $\operatorname{LogDet}$ tree and overall the results suggest that similar datasets yield broadly similar trees for the molecular data regardless of the method of analysis. The same cannot be said for the parsimony trees. These exhibit far more inconsistency and are highly sensitive to the character sets from which they are built. This is at its most extreme for the optimal morphological tree whose comparisons yielded the lowest eight similarity values of the entire analysis, ranging from 0.40 to 0.56 . Of these the lowest was with the combined parsimony tree. This is surprising since this dataset also incorporates the morphological data and perhaps reflects the inherent incompatibility between the molecular and morphological datasets.

\section{The effect of missing data}

A potential explanation of the relatively poor performance of the parsimony trees with respect to their apparent inconsistency may arise from the presence of missing data for some taxa. Nine of the 49 taxa examined in this study were missing data for a single gene. This was largely a result of taxon-specific issues relating to primer mismatches. The impact of missing data in parsimony analyses is a subject of much recent debate, particularly in the context of fragmentary datasets of fossil data. Recent studies suggest that including taxa with missing data helps eliminate real character conflict and that the phylogenetic hypothesis is diminished if these taxa are excluded (Anderson 2001; Kearney 2002). However, there is little doubt that missing data can have an obfuscatory effect upon phylogenetic relationships in some cases, particularly in promoting the generation of taxa that are topologically unstable in equally optimal trees (Wilkinson 1995). To examine the impact of these missing gene fragments, trees were constructed from the combined and molecular data for only those taxa for which a complete dataset was available. These were compared with those generated from the analyses including all taxa. Positional congruence values were generally higher for all pairwise comparisons than for the equivalent parsimony trees incorporating taxa with missing data. This was particularly noticeable for comparisons with the likelihood and Bayesian trees (values range from 0.66 to 0.82 ). This might suggest that parsimony was better at reconstructing this phylogeny when taxa with missing data are excluded. Despite the exclusion of the missing data, these parsimony trees remain equally as incompatible with the morphological topology as those trees including all taxa. Pairwise comparisons between the morphological tree and the combined/ molecular reduced taxon trees were 0.56 and 0.42 , respectively. Thus, exclusion of taxa with missing molecular data does not improve congruence with the morphological tree.

\section{Discussion}

Summarizing the results of our separate and combined hypotheses (Fig. 9, see below) we conclude that the circumfasciate and noncircumfasciate clades resolved by morphology are artifacts in the study by Smith (2001). No independent 
Fig. 9 Strict consensus of the maximum likelihood and Bayesian estimates of ischnoceran louse phylogeny obtained from the combined molecular datasets. Branches common to the morphological tree are highlighted in bold, and the parsimony reconstruction of the circumfasciate/noncircumfasciate character state is mapped on to those nodes that are not equivocal. Major louse groups sensu Smith (2001) are highlighted.

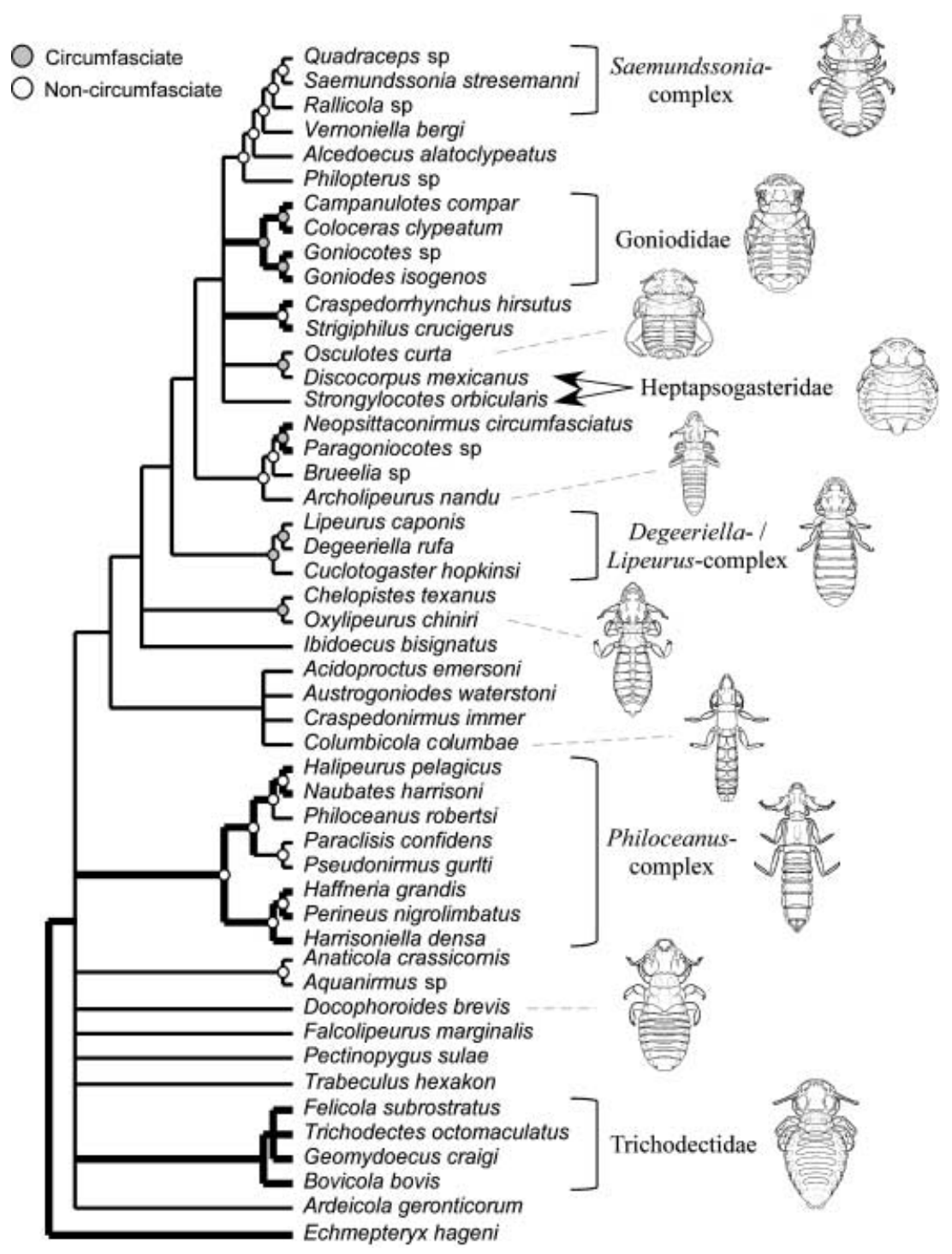

evidence in any of the molecular datasets can be found to support the monophyly of these clades, and when their monophyly is constrained, the resulting trees are a significantly worse explanation of the molecular data than in the unconstrained analyses. However, we do not reject the morphological data outright, and significant problems with the available molecular data temper our conclusions on the phylogeny of avian Ischnocera. These analyses clearly show that whilst the molecular data strongly conflict with the morphological data, partitions of the former strongly conflict with each other, and that the resulting topologies are highly sensitive to both the method of analysis and the data partitions included. Under these circumstances we are confronted with three options: (1) accept a 'preferred' topology from the molecular or morphological dataset; (2) accept some combination of a combined data topology from simultaneous analysis or consensus, or (3) obtain more data. These are considered below:

\section{Accept a 'preferred' topology}

This is perhaps the least desirable option since it is the least likely to globally explain the variation within the different datasets. Only if we had a compelling reason to reject one or more datasets in favour of another would this option be acceptable, and whilst we have demonstrated specific problems with each data partition, it is difficult to objectively exclude one or more data type at the expense of another. Based on the plots derived from pairwise comparisons of sequences, both mitochondrial datasets show strong evidence of multiple substitutions, and this is often advocated as a compelling reason to exclude data from phylogenetic analyses. 
However, homoplastic data can still provide meaningful phylogenetic information, even when sequences no longer show an increase in distance with increasing divergence (Kjer et al. 2001). Character-based phylogenetic methods are able to isolate homoplasy in different parts of the tree if enough taxa are sampled, and several studies have shown that removal of apparently noisy data partitions is inadvisable since these partitions can contain regions of structured data at different levels within the phylogeny (Källersjö et al. 1999; Broughton et al. 2000). In the EF1- $\alpha$ data there is limited character variation except at third positions. However, much of this variation is highly structured as revealed by the Splits Tree and Likelihood mapping analyses. The short length of these sequences may explain why many of these splits are poorly supported (Zharkikh \& Li 1992).

Despite the lack of support for the principal basal clades highlighted by morphology we are not inclined to reject the morphological data outright. Congruence is considerably greater in lower, more terminal portions of the tree spanning levels of divergence at and below the family level, and several independent studies of ischnoceran louse phylogeny have shown a high level of congruence between molecular and morphological data when subfamilial relationships have been investigated. Examples of congruent molecular and morphological phylogenetic studies include those of galliform and columbiform lice (Smith 2000; Johnson et al. 2001a), swiftlets (Clayton et al. 1996; Page et al. 1998), and pocket gopher lice (Hafner et al. 1994; Page et al. 1995). In Smith's (2001) dataset, characters that resolve the basal portions of the morphological tree are closely associated with those features used by the louse to anchor itself to its host, and the ecological niche in which the louse lives. These reflect the dominant features of louse morphology. It is possible that strong, uniform adaptive pressures due to environmental factors (airflow, incessant movement of feathers, uniform food source and so on) may promote convergence in morphology among unrelated taxa living in the similar microhabitats (e.g. vane surface, inside of the quill, down feathers, etc.). Indeed, the hosts themselves are likely to act as strong selection agents, forcing lice living in different host niches (e.g. the head or wings) to adopt a convergent morphology to escape the effects of host preening. However, convergence operating at the deeper level does not necessarily exclude all the morphological data. Indeed it may be possible to re-evaluate homology assessment for these basal characters in the light of evidence from the molecular data, or weight those characters associated with the ecological niche in which the louse lives in a combined analysis.

\section{Accept a combined or consensus topology}

The result of the overall combined partitions analysis of the morphological and molecular data is of concern because of the strong character conflict between these two partitions. Combining these data in a single 'total evidence' analysis (Kluge 1989) may be intuitively the most objective approach. However, based on our analyses of incongruence it would be unwise to present such a tree as our best estimate of ischnoceran louse phylogeny. Several partitions of the molecular data are highly saturated, and under such circumstances parsimony performs poorly at reconstructing phylogeny when evaluated by branch support (Zharkikh \& Li 1992), congruence between gene fragments, and in comparison to previous lower level studies of ischnoceran louse phylogeny. However, combining the molecular and morphological data constrains the method of analysis to parsimony. Missing data, present for some gene fragments also appear to interfere with the parsimony reconstruction, whereas likelihood and Bayesian methods appear less sensitive to this. As highlighted by the ordination of partition metric scores, this global tree does represent a compromise between the topologies from separate analyses. However, it includes several unorthodox relationships that have not been found with other methods of analysis or any combination of the molecular dataset.

The ILD test rejects combining all datasets except those derived from mitochondrial genes. Nevertheless, it has come under some criticism of late (Dolphin et al. 2000), particularly on the grounds that combining noisy datasets can of itself generate a significant ILD result. Indeed when rates of nucleotide substitution are dramatically different, as is the case here, datasets are particularly likely to fail the test (Barker \& Lutzoni 2002; Darlu \& Lecointre 2002). These studies suggest that the test has only limited power to detect incongruence caused by differences in the evolutionary conditions or in the tree topology, except when numerous characters are present and when the site-to-site substitution rate is homogeneous.

Topological congruence between the likelihood and Bayesian analyses of the molecular datasets was relatively high. However, there remain unsettling areas of disagreement between the gene fragments and analytical methods, particularly towards the base of these trees.

An attempt to summarize these molecular hypotheses is presented in Fig. 9. This shows a strict consensus of the trees from the complete likelihood (Fig. 6A) and Bayesian (Fig. 6C) analyses. Branches held in common with the optimal tree derived from morphology are highlighted in bold, and the principal ischnoceran louse clades are identified on the right hand side. These are considered below:

The family Goniodidae from galliform and columbiform birds has been accepted in a number of recent studies on louse phylogeny (Mey 1997; Smith 2000; Johnson et al. 2001a). However, several recent checklists (e.g. Palma \& Barker 1996; Price et al. 2003) fail to acknowledge this group, perhaps because giving it family status would render 
Philopteridae paraphyletic. Uncertainty persists over their precise generic content beyond those taxa sampled here. However, both molecular and morphological data support either a separate galliform and columbiform clade, or a convex (sensu Meacham \& Duncan 1987) grade of galliform lice basal to the columbiform taxa.

Monophyly of the Philoceanus-complex has been less well considered in previous discussions of ischnoceran louse classification. However, this group of eight genera is irrefutably monophyletic, present with high bootstrap, Bremer support, and posterior probability values in all analyses. Largely confined to procellariiform seabirds, it is the most well sampled clade in the dataset, with only three genera (Bedfordiella, Episbates and Pelmatocerandra) absent from the analysis. In Eichler's (1963) classification of Ischnocera he named this family the Pseudonirmidae, elevating it from the subfamilial rank Pseudonirminae. Since the monophyly of this clade is maintained when unpublished sequences of the missing genera are included in the combined molecular analyses, it seems acceptable to use this name in subsequent reference to this group.

Likewise, the mammalian louse family Trichodectidae is monophyletic. This is without doubt the most robust ischnoceran clade, and despite the relatively poor sampling in this study, had been recognized by virtually all louse systematists since its conception by Kellogg (1896). Trichodectidae are arguably the most well studied group of all lice, notwithstanding the human louse family Pediculidae (Phthiraptera: Anoplura). A complete phylogeny for all 350+ species was produced by Lyal (1985), and more recently the Neotrichodectinae (Geomydoecus and allies) from North American pocket gophers have been subject to the most intensive study by Mark Hafner and colleagues in pursuit of a model system for studying cospeciation (Hafner \& Nadler 1988; Hafner et al. 1994; Reed et al. 2000).

Outside these three core clades, discrepancies persist between datasets over the remaining groups originally defined by Smith (2001).

Despite their distinctive morphology and unique host associations, the Heptapsogasteridae from Tinamiformes (tinamou) are not monophyletic in either the molecular or morphological trees. This is the one group of avian Ischnocera on which most phthirapterists agree, and even the most conservative louse systematists (e.g. Hopkins \& Clay 1952; Emerson 1982) have accepted this group without question. Various explanations have been proposed by both Cruickshank et al. (2001) and Smith (2001) to explain the polyphyly (molecular) or paraphyly (morphology) of this group in both datasets and these will not be replicated here. However, the poor sampling of this clade in both studies is likely to be a major contributory factor to this result.

Docophoroides and Trabeculus are two body louse genera associated with procellariiform seabirds. Smith originally placed them in the Saemundssonia-complex, a group largely associated with Charadriiformes (shorebirds, skuas and gulls) and this relationship is supported by the re-analysis presented here. However, the molecular data strongly refute this association, and whilst these genera are sister taxa in all but the combined likelihood analysis, their position in the ischnoceran tree remains unclear. Bayesian analyses of the molecular data partitions placed this pair sister to the Pseudonirmidae of Procellariiformes, whilst the likelihood analyses placed them toward the base of the tree.

The present data do not irrefutably rule out the monophyly of the avian Ischnocera (Philopteridae). Molecular data place Pectinopygus, Ardeicola and Falcolipeurus all close to the base of the ischnoceran tree in various combinations with the mammalian Trichodectidae, and it is clear that these relationships are close to the limits of resolution for these genes. Despite the reduced sampling, similar relationships are suggested by the available $18 \mathrm{~S}$ rRNA data, supporting a basal position for both Pectinopygus and the Trichodectidae (Barker et al. in press). Should the monophyly of the Philopteridae be confirmed with additional data, either its rank will require elevation, or its major containing clades (e.g. Goniodidae, Heptapsogasteridae, etc.) will require demotion. In these circumstances since the Trichodectidae would share the same rank as the Philopteridae, the latter option is arguably the more parsimonious, since a classification within the Philopteridae has yet to be firmly established.

\section{Obtain more data}

Given the limitations of each dataset and the difficulty of objectively excluding one in favour of another, obtaining more data is clearly a prerequisite to a robust phylogeny for avian lice. From the morphological perspective, obtaining more characters, re-evaluating homology assessments in the light of the available molecular data, and improved taxon sampling will yield fresh insights into character convergence and ischnoceran louse phylogeny. Within the context of the molecular data, obtaining sequences for new genes (preferably nuclear) is required. Indeed, throughout this study, repeated attempts have been made to optimize new genes for PCR. However, to date these have met with limited success. Rapid rates of sequence evolution in lice (Johnson et al. 2003), limited success with 'universal' nuclear gene insect primers, and a constant battle with the limited quantities of DNA in most louse species have conspired to make finding alternative molecular markers an extremely time consuming and difficult task. Given these problems, one solution would be to obtain longer stretches of those sequences that can be readily amplified, particularly for the nuclear gene EF1- $\alpha$. However, simulation studies suggest the likely benefits from such a strategy would be, at best, marginal. Likelihood mapping analysis of EF1- $\alpha$ datasets simulated using Seq-General 
A. $1000 \mathrm{bp}$
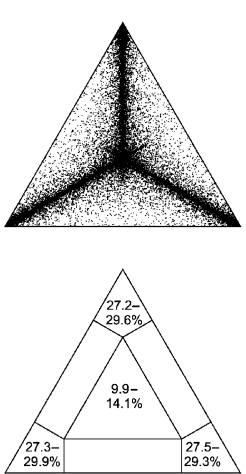

B. $2000 \mathrm{bp}$
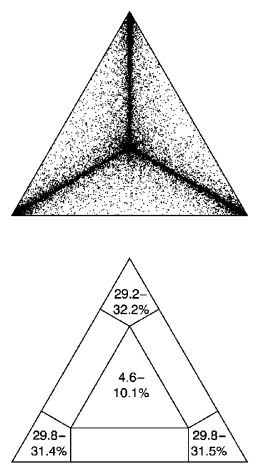

C. $3000 \mathrm{bp}$
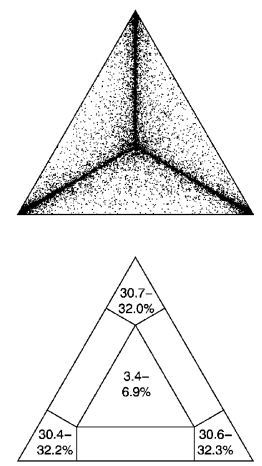

D. $4000 \mathrm{bp}$
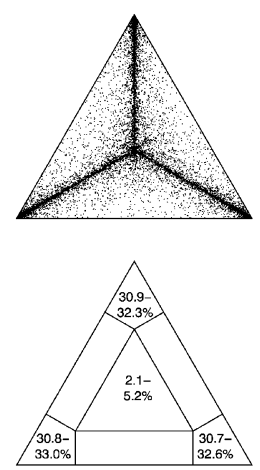

Fig. 10 Likelihood maps of simulated EF1- $\alpha$ data at varying dataset sizes (10 replicates each for 1000, 2000, 3000 and $4000 \mathrm{bp}$ ).
(Rambaut \& Grassly 1997), based on the optimal tree, parameters and model determined from the available $348 \mathrm{bp}$ fragment, suggests that between 3 and 4 kb of EF1- $\alpha$ would be required to obtain a dataset that is strongly tree-like (Fig. 10). This assessment makes the assumption that the rate of evolution in the fragment already recovered is typical for the rest of this gene. Nonetheless, as there are presently only five EF1- $\alpha$ insect sequences in GenBank larger than $2500 \mathrm{bp}$, and given the relatively poor performance of simulated louse fragments even at this size, it would seem folly to pursue such a strategy for Ischnocera. Even the relatively conserved nuclear gene $18 \mathrm{~S}$ rRNA appears to perform poorly within Ischnocera, compared with other louse suborders (Fig. 11). Splits Tree and likelihood maps for Ischnocera suggest that these data contain very little tree-like phylogenetic signal for ischnoceran chewing lice (Fig. 11A). However, this marker performs reasonably well for Amblycera and is strongly tree-like for Anoplura (Fig. 11C). Whilst $18 \mathrm{~S}$ shows considerable promise for the latter two groups, clearly other markers are needed for Ischnocera, and given the haphazard results from attempting to optimize select nuclear genes in lice to date, a better means of searching for them is also required.

The relative ease with which cloned DNA libraries can now be generated offers a cost effective means of identifying new markers specific to selected taxa (Theodorides et al. 2002), and is the obvious next step to improving our understanding of avian louse phylogeny. However, taking a broader perspective, it is perhaps not surprising that our first efforts to resolve bird louse relationships have met with limited success.

\section{A. Ischnocera}
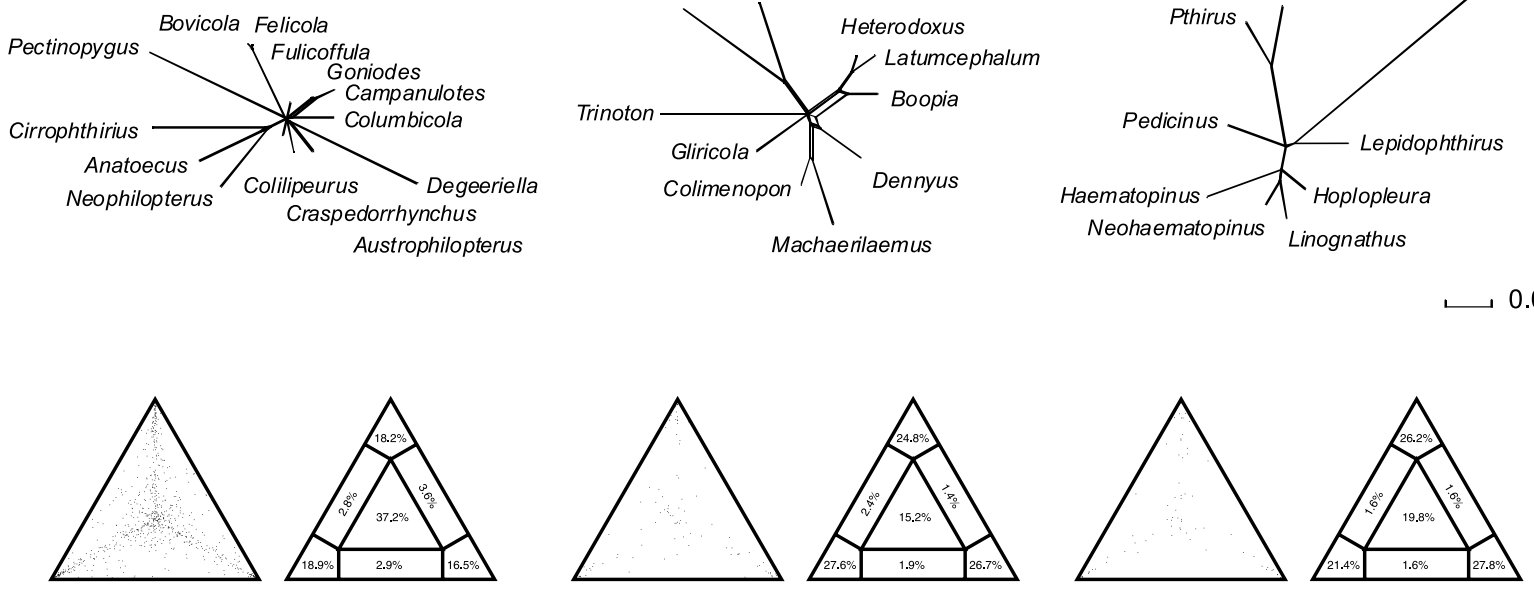

Fig. 11 Likelihood maps and Splits Tree analyses of an aligned $1311 \mathrm{bp}$ fragment of nuclear 18S rRNA data for each phthirapteran suborder from Barker et al. (in press). All branches are drawn with proportional edge lengths to the same scale. This gene performs relatively well (i.e. contains strong tree-like phylogenetic signal) within the louse suborders Amblycera and Anoplura, but is considerably weaker for Ischnocera. 
Presupposing that louse diversification is a function of cospeciation with their hosts, it may take considerably more effort before a robust phylogeny for avian lice is resolved. Early attempts to resolve bird phylogeny met with similar difficulties, and arguably the deep branch phylogeny of birds is still in a similarly parlous state, despite receiving several orders of magnitude more attention than the phylogeny of their lice.

\section{Acknowledgements}

We would like to thank those who assisted with the collection of material: R.J. Adams, Terry Chesser, Dale Clayton, Mark Hafner, Chris Lyal, Ben Marks, Ian Mason, Kevin McCracken, Rob Moyle, Ricardo Palma, Robert Palma, David Reed, Jason Weckstein, John Wombey, and Bernie Zonfrillo. Special thanks to Roger Price and Ricardo Palma who helped with the identification of selected taxa, and with the assistance of Robert Dalgleish provided useful discussions on the taxonomic component of this paper. We would especially like to thank the DNA sequencing facilities at the Universities of Glasgow, Utah and Illinois Natural History Survey, plus David Morris and two anonymous reviewers for their helpful discussions and careful reading of the manuscript. This research was supported by a Wellcome Trust biodiversity fellowship to Vince Smith (063734/Z/01/Z); a NSF grant to Kevin Johnson (DEB-0107891) and NERC grant GR3/11075 to Roderic Page.

\section{References}

Akaike, H. (1974). A new look at the statistical model identification. IEEE Transactions on Automatic Contrology, 19, 716-723.

Anderson, J. S. (2001). The phylogenetic trunk: Maximal inclusion of taxa with missing data in an analysis of the Lepospondyli (Vertebrata, Tetrapoda). Systematic Biology, 50, 170-193.

Archie, J. W. (1989). A randomisation test for phylogenetic information in systematic data. Systematic Zoology, 38, 239-252.

Bandelt, H.-J. \& Dress, A. W. M. (1992). Split decomposition: a new and useful approach to phylogenetic analysis of distance data. Molecular Phylogenetics and Evolution, 1, 242-252.

Barker, F. K. \& Lutzoni, F. M. (2002). The utility of the incongruence length difference test. Systematic Biology, 51, 625-637.

Barker, S. C., Whiting, M., Johnson, K. P. \& Murrell, A. (2003). Phylogeny of the lice (Insecta: Phthiraptera) inferred from small subunit rRNA. Zoologica Scripta, 32, 407-417.

Blagoveshtchenskii, D. I. (1956). Stroenie i. systematicheskoe znacenie polovejsistemy puchoedov (Mallophaga) [The structure and significance of the sexual systems of the Mallophaga]. Parazitologieeskij Zbornik, 16, 5-88 [in Russian].

Bremer, K. (1988). The limits of amino-acid sequence data in angiosperm phylogenetic reconstruction. Evolution, 42, 795-803.

Broughton, R. E., Stanley, S. E. \& Durrett, R. T. (2000). Quantification of homoplasy for nucleotide transitions and transversions and a reexamination of assumptions in weighted phylogenetic analysis. Systematic Biology, 49, 617-627.

Carpenter, J. M., Goloboff, P. A. \& Farris, J. S. (1998). PTP is meaningless, T-PTP is contradictory: a reply to Trueman. Cladistics, 14, $105-116$.
Choe, J. C. \& Kim, K. C. (1988). Microhabitat preference and coexistence of ectoparasitic arthropods on Alaskan seabirds. Canadian Journal of Zoology, 66, 987-997.

Clay, T. (1949). Some problems in the evolution of a group of ectoparasites. Evolution, 3, 279-299.

Clayton, D. H., Al-Tamimi, S. \& Johnson, K. P. (2002). The ecological basis of coevolutionary history. In R. Page (Ed.) Tangled Trees: Phylogeny, Cospeciation and Coevolution (pp. 310-341). Chicago: University of Chicago.

Clayton, D. H., Lee, P. L. M., Tompkins, D. M. \& Brodie, E. D. (1999). Reciprocal natural selection on host-parasite phenotypes. American Naturalist, 154, 261-270.

Clayton, D. H., Price, R. D. \& Page, R. D. M. (1996). Revision of Dennyus (Collodennyus) lice (Phthiraptera: Menoponidae) from swiftlets, with descriptions of new taxa and a comparison of hostparasite relationships. Systematic Entomology, 21, 179-204.

Clayton, D. H. \& Walther, B. A. (1997). Appendix C: collection and quantification of arthropod parasites of birds. In D. H. Clayton \& J. Moore (Eds) Host-Parasite Evolution: General Principles and Avian Models (pp. 419-440). Oxford: Oxford University Press.

Corpet, F. \& Michot, B. (1994). RNAlign program: alignment of RNA sequences using both primary and secondary structures. Computer Applications in the Biosciences, 10, 389-399.

Cruickshank, R. H., Johnson, K. P., Smith, V. S., Adams, R. J., Clayton, D. H. \& Page, R. D. M. (2001). Phylogenetic analysis of partial sequences of Elongation Factor 1 identifies major groups of lice (Insecta: Phthiraptera). Molecular Phylogenetics and Evolution, 19, 202-215.

Cunningham, C. W. (1997). Can three incongruence tests predict when data should be combined? Molecular Biology and Evolution, 14, 733-740.

Danforth, B. N. \& Ji, S. (1998). Elongation factor- $1 \alpha$ occurs as two copies in bees: implications for phylogenetic analysis of EF-1 $\alpha$ in insects. Molecular Biology and Evolution, 15, 225-235.

Darlu, P. \& Lecointre, G. (2002). When does the incongruence length difference test fail? Molecular Biology and Evolution, 19, 432-437.

DeRijk, P. \& DeWachter, R. (1997). RnaViz, a program for the visualisation of RNA secondary structure. Nucleic Acids Research, 25, 4679-4684.

Dolphin, K., Belshaw, R., Orme, C. D. L. \& Quicke, D. L. J. (2000). Noise and incongruence: interpreting results of the incongruence length difference test. Molecular Phylogenetics and Evolution, 17, 401-406.

Eichler, W. D. (1963). Arthropoda. Insecta. Phthiraptera I. Mallophaga. In H. G. Bronns (Ed.) Klassen und Ordnungen Des Tierreichs III Insecta $7 b$ Phthiraptera. Leipzig: Geost \& Portig.

Emerson, K. C. (1982). Mallophaga. In S. P. Parker (Ed.) Synopsis and Classification of Living Organisms (pp. 409-415). New York: McGraw-Hill Inc.

Eriksson, T. (1997). Autodecay, Version 2.9.9. Available via http:// www.bergianska.se/personal/TorstenE/

Estabrook, G. F. (1992). Evaluating undirected positional congruence of individual taxa between two estimates of the phylogenetic tree for a group of taxa. Systematic Biology, 41, 172-177.

Faith, D. P. \& Cranston, P. S. (1991). Could a cladogram this short have arisen by chance alone? On permutation tests for cladistic structure. Cladistics, 7, 1-28.

Farris, J. S., Källersjö, M., Kluge, A. G. \& Bult, C. (1994a). Permutations. Cladistics, 10, 65-76. 
Farris, J. S., Källersjö, M., Kluge, A. G. \& Bult, C. (1994b). Testing significance of incongruence. Cladistics, 10, 315-319.

Felsenstein, J. (1985). Confidence limits on phylogenies: an approach using the bootstrap. Evolution, 39, 783-791.

Goldman, N., Anderson, J. P. \& Rodrigo, A. G. (2000). Likelihoodbased tests of topologies in phylogenetics. Systematic Biology, 49, 652-670.

Hafner, M. S. \& Nadler, S. A. (1988). Phylogenetic trees support the coevolution of parasites and their hosts. Nature, 332, 258-259.

Hafner, M. S. \& Nadler, S. A. (1990). Cospeciation in host-parasite assemblages: comparative analysis of rates of evolution and timing of cospeciation events. Systematic Biology, 39, 192-204.

Hafner, M. S., Sudman, P. D., Villablanca, F. X., Spradling, T. A., Demastes, J. W. \& Nadler, S. A. (1994). Disparate rates of molecular evolution in cospeciating hosts and parasites. Science, 265, $1087-1090$.

Hasegawa, M. \& Hashimoto, T. (1993). Ribosomal-RNA trees misleading. Nature, 361, 23-23.

Hillis, D. M. \& Huelsenbeck, J. P. (1992). Signal, noise and reliability in molecular phylogenetic analyses. Fournal of Heredity, 83, 189-195.

Hillis, D. M., Mable, B. K. \& Moritz, C. (1996). Applications of molecular systematics: the state of the field and a look at the future. In D. M. Hillis, C. Moritz \& B. K. Mable (Eds) Molecular Systematics (pp. 515-543). Sunderland, MA: Sinauer Associates.

Hopkins, G. H. E. \& Clay, T. (1952). A Checklist of the Genera and Species of Mallophaga. London: British Museum of Natural History.

Huelsenbeck, J. P. (1991). Tree-length distribution skewness — an indicator of phylogenetic information. Systematic Zoology, 40, 257 270.

Huelsenbeck, J. P. \& Ronquist, F. (2001). MR-BAYES: Bayesian inference of phylogeny. Bioinformatics, 17, 754-755.

Huson, D. H. (1998). SplitsTree: analyzing and visualizing evolutionary data. Bioinformatics, 14, 68-73.

Johnson, K. P., Adams, R. J. \& Clayton, D. H. (2001a). Molecular systematics of Goniodidae (Insecta: Phthiraptera). Fournal of Parasitology, 87, 862-869.

Johnson, K. P. \& Clayton, D. H. (2003). The biology, ecology and evolution of chewing lice. In R. D. Price, R. A. Hellenthal \& R. L. Palma (Eds) The Chewing Lice: World Checklist and Biology Overview (pp.) Champaign-Urbana, Illinois: Illinois Natural History Survey.

Johnson, K. P., Cruickshank, R. H., Adams, R. J., Smith, V. S., Page, R. D. M. \& Clayton, D. H. (2003). Dramatically elevated rate of mitochondrial substitution in lice (Insecta: Phthiraptera). Molecular Phylogenetics and Evolution, 26, 231-242.

Johnson, K. P., Moyle, R. G., Witt, C. C., Faucett, R. C. \& Weckstein, J. D. (2001b). Phylogenetic relationships in the louse genus Penenirmus based on nuclear (EF-1 alpha) and mitochondrial (COI) DNA sequences. Systematic Entomology, 26, 491-497.

Johnson, K. P., Weckstein, J. D., Witt, C. C., Faucett, R. C. \& Moyle, R. G. (2002). The perils of using host relationships in parasite taxonomy: phylogeny of the Degeeriella complex. Molecular Phylogenetics and Evolution, 23, 150-157.

Johnson, K. P. \& Whiting, M. F. (2002). Multiple genes and the monophyly of Ischnocera (Insecta: Phthiraptera). Molecular Phylogenetics and Evolution, 22, 101-110.

Jow, H., Hudelot, C., Rattray, M. \& Higgs, P. G. (2002). Bayesian phylogenetics using an RNA substitution model applied to early mammalian evolution. Molecular Biology and Evolution, 19, 15911601.

Källersıö, M., Albert, V. A. \& Farris, J. S. (1999). Homoplasy increases phylogenetic structure. Cladistics, 15, 91-93.

Källersjö, M., Farris, J. S., Kluge, A. G. \& Bult, C. (1992). Skewness and permutation. Cladistics, 8, 275-287.

Kearney, M. (2002). Fragmentary taxa, missing data, and ambiguity: mistaken assumptions and conclusions. Systematic Biology, 51, 369381.

Kellogg, V. L. (1896). New Mallophaga, I, - with special reference to a collection made from maritime birds of the Bay of Monterey, California. Proceedings of the Californian Academy of Science - 2nd Series, 6, 31-196.

Kjer, K. M., Blahnik, R. J. \& Holzenthal, R. W. (2001). Phylogeny of Trichoptera (caddisflies): Characterization of signal and noise within multiple datasets. Systematic Biology, 50, 781-816.

Kluge, A. G. (1989). A concern for evidence and a phylogenetic hypothesis of relationships among Epicrates (Boidae, Serpentes). Systematic Zoology, 38, 7-25.

Königsmann, E. (1960). Zur Phylogenie der Parametabola. Beiträge zur Entomologie, 10, 705-744.

Lockhart, P. J., Larkum, A. W. D., Steel, M. A., Waddell, P. J. \& Penny, D. (1996). Evolution of chlorophyll and bacteriochlorophyll: the problem of invariant sites in sequence analysis. Proceedings of the National Academy of Sciences of the USA, 93, 1930-1934.

Lockhart, P. J., Steel, M. A., Barbrook, A. C., Huson, D. H., Charleston, M. A. \& Howe, C. J. (1998). A covariotide model explains apparent phylogenetic structure of oxygenic photosynthetic lineages. Molecular Biology and Evolution, 15, 1183-1188.

Lockhart, P. J., Steel, M. A., Hendy, M. D. \& Penny, D. (1994). Recovering evolutionary trees under a more realistic model of sequence evolution. Molecular Biology and Evolution, 11, 605-612.

Lopez, P., Casane, D. \& Philippe, H. (2002). Heterotachy, an important process of protein evolution. Molecular Biology and Evolution, 19, $1-7$.

Loye, J. E. \& Zuk, M. (1991). Bird-parasite interactions. Ecology, Evolution and Behaviour. Oxford: Oxford University Press.

Lyal, C. H. C. (1985). Phylogeny and classification of the Psocodea, with particular reference to lice (Psocodea: Phthiraptera). Systematic Entomology, 10, 145-165.

Maddison, W. P. \& Maddison, D. R. (1992). MacClade: Analysis of Phylogeny and Character Evolution. [Computer software and manual]. Sunderland, MA: Sinauer Associates.

Meacham, C. A. \& Duncan, T. (1987). The necessity of convex groups in biological classification. Systematic Botany, 12, 78-90.

Mey, E. (1994). Beziehungen zwischen Larvemorphologie und systematik der adulti bei den vogel — Ischnozeren (Insecta, Phthiraptera, Ischnocera). Mitteilungen Aus Dem Zoologischen Museum, Berlin, 70, 3-84.

Mey, E. (1997). Die Goniodiden (Insecta, Phthiraptera, Ischnocera) der Großfußhühner (Megapodiidae). Rudolstädter Naturbistorische Schriften, 8, 19-44.

Page, R. D. M. (1993). COMPONENT. Tree Comparison Software for Microsoft Windows. [Computer software and manual]. London: The Natural. History Museum.

Page, R. D. M. (2000). Comparative analysis of secondary structure of insect mitochondrial small subunit ribosomal RNA using maximum weighted matching. Nucleic Acids Research, 28, 38393845. 
Page, R. D. M. (2002). Introduction. In R. Page (Ed.) Tangled Trees: Phylogeny, Cospeciation and Coevolution (pp. 1-21). Chicago: University of Chicago.

Page, R. D. M., Clayton, D. H. \& Paterson, A. M. (1996). Lice and cospeciation: a response to Barker. International Fournal for Parasitology, 26, 213-218.

Page, R. D. M., Cruickshank, R. H. \& Johnson, K. P. (2002). Louse (Insecta: Phthiraptera) mitochondrial 12S rRNA secondary structure is highly variable. Insect Molecular Biology, 11, 361-369.

Page, R. D. M., Lee, P. L. M., Becher, A. S., Griffiths, R. \& Clayton, D. H. (1998). A different tempo of mitochondrial evolution in birds and their parasitic lice. Molecular Phylogenetics and Evolution, 9, 276-293.

Page, R. D. M., Price, R. D. \& Hellenthal, R. A. (1995). Phylogeny of Geomydoecus and Thomomydoecus pocket gopher lice (Phthiraptera: Trichodectidae) inferred from cladistic analysis of adult and first instar morphology. Systematic Entomology, 20, 129-143.

Palma, R. L. \& Barker, S. C. (1996). Phthiraptera. In A. Wells (Ed.) Psocoptera, Phtbiraptera, Thysanoptera (pp. 81-247, 333-361, 373396). Melbourne: CSIRO.

Posada, D. \& Crandall, K. A. (1998). Modeltest: Testing the model of DNA substitution. Bioinformatics, 14, 817-818.

Price, R. D., Hellenthal, R. A., Palma, R. L., Johnson, K. P. \& Clayton, D. H. (2003). The Chewing Lice: World Checklist and Biology Overview. Champaign-Urbana, Illinois: Illinois Natural History Survey.

Rambaut, A. \& Grassly, N. C. (1997). Seq-General: an application of the Monte Carlo simulation of DNA sequence evolution along phylogenetic trees. Computer Applications in the Biosciences, 13, 235-238.

Reed, D. L., Hafner, M. S., Allen, S. K. \& Smith, M. B. (2000). Spatial partitioning of host habitat by chewing lice of the genera Geomydoecus and Thomomydoecus (Phthiraptera: Trichodectidae). Fournal of Parasitology, 86, 951-955.

Rózsa, L. (1993). Speciation patterns of ectoparasites and 'straggling' lice. International fournal for Parasitology, 23, 859-864.

Rózsa, L., Rékási, J. \& Reiczigel, J. (1996). Relationship of host coloniality to the population ecology of avian lice (Insecta: Phthiraptera). Fournal of Animal Ecology, 65, 242-248.

Rzhetsky, A. \& Nei, M. (1995). Tests of applicability of several substitution models for DNA sequence data. Molecular Biology and Evolution, 12, 131-151.
Simon, C., Frati, F., Beckenbach, A., Crespi, B., Liu, H. \& Flook, P. (1994). Evolution, weighting, and phylogenetic utility of mitochondrial gene sequences and a compilation of conserved polymerase chain reaction primers. Annals of the Entomolecular Society of America, 87, 651-704.

Smith, V. S. (2000). Basal ischnoceran louse phylogeny (Phthiraptera: Ischnocera: Goniodidae and Heptapsogasteridae). Systematic Entomology, 25, 73-94.

Smith, V. S. (2001). Avian louse phylogeny (Phthiraptera: Ischnocera): a cladistic study based morphology. Zoological Fournal of the Linnean Society, 132, 81-144.

Strimmer, K. \& Haeseler, A. V. (1997). Likelihood mapping: a simple method to visualize phylogenetic content of a sequence alignment. Proceedings of the National Academy of Sciences of the USA, 94, 6815-6819.

Swofford, D. L. (2002). PAUP*. Phylogenetic Analysis Using Parsimony (*and Other Methods) [Computer software and manual]. Sunderland, MA: Sinauer Associates.

Theodorides, K., De Riva, A., Gomez-Zurita, J., Foster, P. G. \& Vogler, A. P. (2002). Comparison of EST libraries from seven beetle species: towards a framework for phylogenomics of the Coleoptera. Insect Molecular Biology, 11, 467-475.

Thompson, J. D., Gibson, T. J., Plewniak, F., Jeanmougin, F. \& Higgins, D. G. (1997). The ClustalX windows interface: flexible strategies for multiple sequence alignment aided by quality analysis tools. Nucleic Acids Research, 24, 4876-4882.

Thorley, J. L. \& Page, R. D. M. (2000). RadCon: phylogenetic tree comparison and consensus. Bioinformatics, 16, 486-487.

Wheeler, W. C. \& Gladstein, D. (1995). Malign 25. [Computer software and manual]. New York: American Museum of Natural History.

Wilkinson, M. (1995). Coping with abundant missing entries in phylogenetic inference using parsimony. Systematic Biology, 44, 501514.

Wilkinson, M., Peres-Neto, P. R., Foster, P. G. \& Moncrieff, C. B. (2002). Type 1 error rates of the permutation tail probability test. Systematic Biology, 51, 524-527.

Zharkikh, A. \& Li, W. H. (1992). Statistical properties of bootstrap estimation of phylogenetic variability from nucleotide-sequences. II. Four taxa without a molecular clock. Fournal of Molecular Evolution, 35, 356-366. 